San Jose State University

SJSU ScholarWorks

Master's Theses

Master's Theses and Graduate Research

1992

\title{
Growth of polycrystalline ZnS by MOCVD using thiophene as a sulfur source
}

William H. Perez

San Jose State University

Follow this and additional works at: https://scholarworks.sjsu.edu/etd_theses

\section{Recommended Citation}

Perez, William H., "Growth of polycrystalline ZnS by MOCVD using thiophene as a sulfur source" (1992). Master's Theses. 494.

DOI: https://doi.org/10.31979/etd.2spp-3ph2

https://scholarworks.sjsu.edu/etd_theses/494

This Thesis is brought to you for free and open access by the Master's Theses and Graduate Research at SJSU ScholarWorks. It has been accepted for inclusion in Master's Theses by an authorized administrator of SJSU ScholarWorks. For more information, please contact scholarworks@sjsu.edu. 


\section{INFORMATION TO USERS}

This manuscript has been reproduced from the microfilm master. UMI films the text directly from the original or copy submitted. Thus, some thesis and dissertation copies are in typewriter face, while others may be from any type of computer printer.

The quality of this reproduction is dependent upon the quality of the copy submitted. Broken or indistinct print, colored or poor quality illustrations and photographs, print bleedthrough, substandard margins, and improper alignment can adversely affect reproduction.

In the unlikely event that the author did not send UMI a complete manuscript and there are missing pages, these will be noted. Also, if unauthorized copyright material had to be removed, a note will indicate the deletion.

Oversize materials (e.g., maps, drawings, charts) are reproduced by sectioning the original, beginning at the upper left-hand corner and continuing from left to right in equal sections with small overlaps. Each original is also photographed in one exposure and is included in reduced form at the back of the book.

Photographs included in the original manuscript have been reproduced xerographically in this copy. Higher quality $6 " \mathrm{x} 9$ " black and white photographic prints are available for any photographs or illustrations appearing in this copy for an additional charge. Contact UMI directly to order.

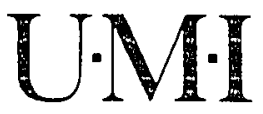

University Microfıms Internatıonal

A Bell \& Howell Information Company 
Order Number 1351065

Growth of polycrystalline ZnS by MOCVD using thiophene as a sulfur source

Perez, William Henry, M.S.

San Jose State University, 1992 



\title{
GROFTH OF POLYCRYSTALLINE ZnS BY MOCVD USING THIOPHENE AS A SULFUR BOURCE
}

\author{
A Thesis \\ Presented to \\ The Faculty of the Department of Materials Engineering \\ san Jose state University
}

In Partial Fulfillment of the Requirements for the Degrae Master of science

by

William H. Perez

December, 1992 
APPROVED FOR THE DEPARTMENT OF MATERIALS ENGINEERING
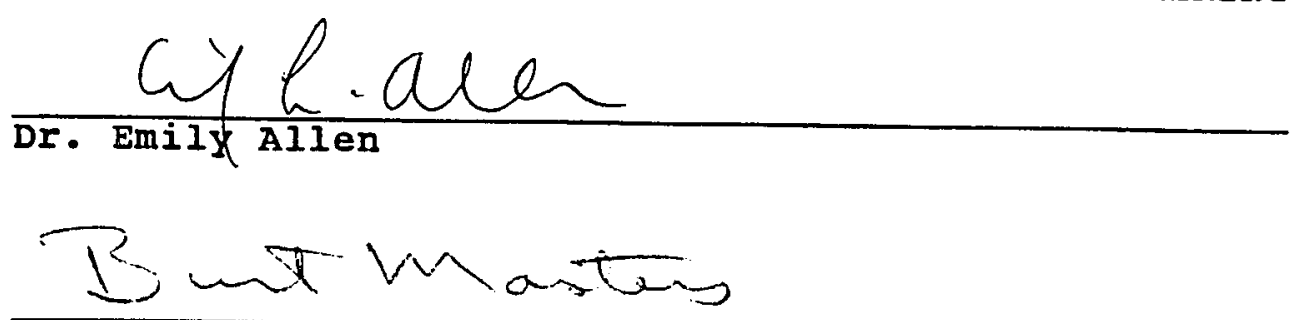

Dr. Burt Masters

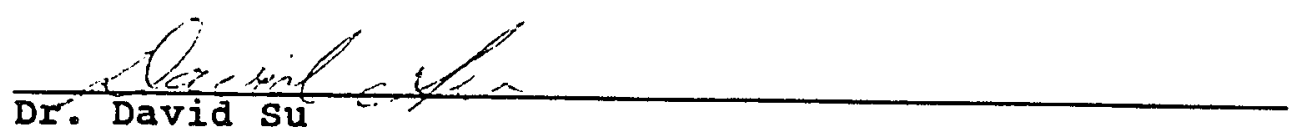

APPROVED FOR THE UNIVERSITY

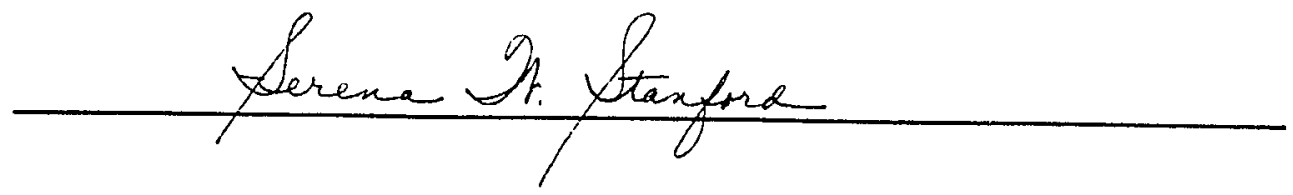




\section{ABSTRACT}

\section{GROWTH OF POLYCRYSTALIINE ZIS BY MOCVD OSING THIOPHENE AS A SULFUR SOURCE}

\section{by William H. Perez}

Deposition of zns thin films by MOCVD (metalorganic chemical vapor deposition) was attempted using $10 \%$ DMZn in helium and liquid thiophene $\left(\mathrm{C}_{4} \mathrm{H}_{4} \mathrm{~S}\right)$ through which helium was bubbled. Growths were conducted at pressures between 1-10 torr and temperatures between $250-500^{\circ} \mathrm{C}$. No $\mathrm{ZnS}$ deposits resulted due to short residence times of thiophene in the reaction chamber.

Deposition was also carried out using hydrogen sulfide $\left(\mathrm{H}_{2} \mathrm{~S}\right)$ in place of thiophene. Good deposits were achieved with growth rates ranging from $0.1-1.1 \mu \mathrm{m} / \mathrm{min}$ over the range of parameters studied. Growth rate trends were evaluated, and the growth rate was found to be directly related to the $\left[\mathrm{H}_{2} \mathrm{~S}+\mathrm{He}\right]$ flow and growth temperature. However, the growth rate was found to be inversely related to the [DMZn + He] flow, which is thought to be caused by the increased [DMZn + He] flow overwhelming the local environment of the susceptor and starving the reaction surface of $\mathrm{H}_{2} \mathrm{~S}$. 


\section{Acknowledgements}

I would like to thank Dr. Burt Masters, my thesis advisor, for his support in this project, and especially for his being available, sometimes on very short notice, when I had questions.

Next, I would like to thank my managers at work, Gary Baldwin, and Ron Moon who hàve supported my continuing studies for the last five years, and especially Mike Ludowise, with whom I work on a daily basis, for being extremely accommodating in the sometimes erratic schedule of a graduate student.

Lastly I'd like to thank my family and friends, cheering me up when my morale was low, and for helping me look ahead to the light at the end of the tunnel. 
Abstract $\ldots \ldots \ldots \ldots \ldots \ldots \ldots \ldots \ldots \ldots \ldots \ldots \ldots$. . . . . . . .

Acknowledgements $\ldots \ldots \ldots \ldots \ldots \ldots \ldots \ldots \ldots \ldots \ldots$ iv

Table of Contents $\ldots \ldots \ldots \ldots \ldots \ldots \ldots \ldots \ldots \ldots \ldots, \ldots \ldots$

List of Tables ......................... vii

List of Figures $\ldots \ldots \ldots \ldots \ldots \ldots \ldots \ldots \ldots \ldots \ldots \ldots$ viii

I. Introduction $\ldots \ldots \ldots \ldots \ldots \ldots \ldots \ldots \ldots \ldots \ldots$

Applications of $\mathrm{zns} \ldots \ldots \ldots \ldots \ldots \ldots \ldots \ldots \ldots \ldots \ldots \ldots$

Deposition Techniques ..................... 5

Atomic Layer Epitaxy $\ldots \ldots \ldots \ldots \ldots \ldots \ldots$

Molecular Beam Epitaxy $\ldots \ldots \ldots \ldots \ldots \ldots \ldots \ldots, \ldots$

Mocvd of zinc sulfide ...................

Sources used in MOCVD of $\mathrm{ZnS} \ldots \ldots \ldots \ldots \ldots \ldots \ldots 14$

Zinc sources ......................... 14

Sulfur sources $\ldots \ldots \ldots \ldots \ldots \ldots \ldots \ldots \ldots \ldots$

Safety of Precursors Used in MOCVD of ZnS ........ 19

Summary of MOCVD Sources for $2 n s \ldots \ldots \ldots \ldots \ldots . \ldots 20$

Kinetics of Reactions by MOCVD ............... 21

II. Fabrication Techniques of zinc Sulfide Devices ....23

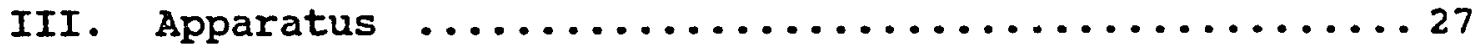

IV. Procedure and Results for Thiophene $\ldots \ldots \ldots \ldots \ldots 33$

v. Procedure and Results for $\mathrm{H}_{2} \mathrm{~S} \ldots \ldots \ldots \ldots \ldots \ldots \ldots \ldots$

VI. Conclusion $\ldots \ldots \ldots \ldots \ldots \ldots \ldots \ldots \ldots \ldots \ldots$ 
VII. References ............................ 59

VIII. Appendix $\ldots \ldots \ldots \ldots \ldots \ldots \ldots \ldots \ldots \ldots \ldots \ldots \ldots \ldots \ldots \ldots \ldots \ldots$

MOCVD operating Procedures .................63 


\section{Iist of Tables}

Page

1. Physical Data for the Commonly Used Sources in 21 the Growth of Zinc Sulfide

2. Vapor Pressure of Thiophene as a Function of Temperature

3. MOCVD of ZnS Run Data using Thiophene as the

4. MOCVD of ZnS Run Data using H2S as the Sulfur Source 


\section{List of Figures}

Page

1. Alpha Particle Scatcering. 3

2. Atomic Layer Epitaxy of Zns. 6

3. Simplified Schematic of an MBE Reactor. 8

4. Gaseous Source MOCVD Reactor. 10

5. Gaseous and Liquid Source MOCVD Reactor. 11

6. Susceptor Geometries Used in MOCVD. 13

7. Alternative Zinc Sources for $\mathrm{ZnS}$ growth. 15

8. Photo-Assisted MOCVD. 17

9. Alternative Sulfur Sources for Zns Growth. 18

10. MOCVD Apparatus 28

11. Schematic of Thiophene Line. 33

12. Surface Morphology of Zns. 43

13. Cross-section of zns. 44

14. Energy Dispersive X-Ray of ZnS. 45

15. Thickness vs. Sulfur Flow at $\mathrm{T}=250^{\circ} \mathrm{C}$. 46

16. Thickness vs. Sulfur Flow at $\mathrm{T}=350^{\circ} \mathrm{C}$. 47

17. Thickness vs. Sulfur Flow at DMZn flow=8 sccm. 48

18. Thickness vs. Sulfur Flow at DMZn flow=10 49

19. Thickness vs. DMZn Flow at $\mathrm{T}=250^{\circ} \mathrm{C}$. 50

20. Thickness vs. DMZn Flow at $\mathrm{T}=350^{\circ} \mathrm{C}$. 51

21. Thickness vs. DMZn Flow at H2S Flow=16 sccm. 52 
22. Thickness vs. DMZn Flow at H2S Flow $=38 \mathrm{sccm}$.

23. Thickness vs. Growth Temp. at DMZn Flow=8

24. Thickness vs. Growth Temp. at DMZn Flow=10 sccm.

25. Thickness vs. Growth Temp. at H2S Flow $=16$

26. Thickness vs. Growth Temp. at H2S Flow $=38$ sccm. 


\section{Introduction}

Over the past 20 years, increasing work has been done with the uses of II/VI compounds such as zinc sulfide (Zns). Today they have applications in uses calling for polycrystalline thin film layers such as thin film electroluminescent devices, as a suspension in liquids in the field of biology where they have been used for marking auto radiograms, and in the production of display screens where ZnS has been used for years for cathode ray tubes (CRT's).

They also have seen use in single crystal applications where their primary function is in blue light emitting diodes (LED'S).

Recent work with $\mathrm{ZnS}$ is reviewed, showing the range of its applications as well as the variety of deposition techniques used to grow it, including atomic layer epitaxy (ALE), molecular beam epitaxy (MBE), and metal organic chemical vapor deposition (MOCVD), the subject of this paper.

There has been a wide variety of sources used in the growth of ZnS by MOCVD. Motivation for the uses of the common ones as well as the one which is the subject of this project, thiophene $\left(\mathrm{C}_{4} \mathrm{H}_{4} \mathrm{~S}\right)$, will be discussed. Among the reasons for using this sulfur source are the safety 
considerations, so the commonly used sources will be reviewed from this standpoint as well.

The objective of this project is to grow $\mathrm{ZnS}$ thin films using the MOCVD reactor here at San Jose State University. Other students who have used this equipment are Marc Jensen, Hoa Do, Hamid Kashani, Rex Chuang, and Richard Patten.

It is also of interest to get an idea of trends of thin film growth with the $\mathrm{H}_{2} \mathrm{~S}$ sulfur source.

\section{Applications of zinc sulfide}

A very important result in science, the theory of atomic structure, was postulated by Sir Ernest Rutherford with the help of zinc sulfide. Geiger and Marsden conducted backscattering experiments under the supervision of Rutherford in 1911 . In their setup, a radioactive source emits $\alpha$-particles which pass through a pinhole in a lead screen. The beam then passes through a thin metal foil made of gold, silver, or copper. The scattered beam from the metal foil finally hits a plate coated with zinc sulfide, where a momentary flash or scintillation is observable at each collision. $(1,2)$ This occurs when electrons in the material are excited from the valence band into the conduction band. When the electron drops back to the valence band, a photon is emitted. If the wavelength of this photon is in the visible range, it is called 
luminescence. When there is a delay in this decay, caused by impurities resulting in energy traps between the conduction and valence bands, the luminescence is called phosphorescence.

A diagram of the experimental setup is shown in Figure 1.

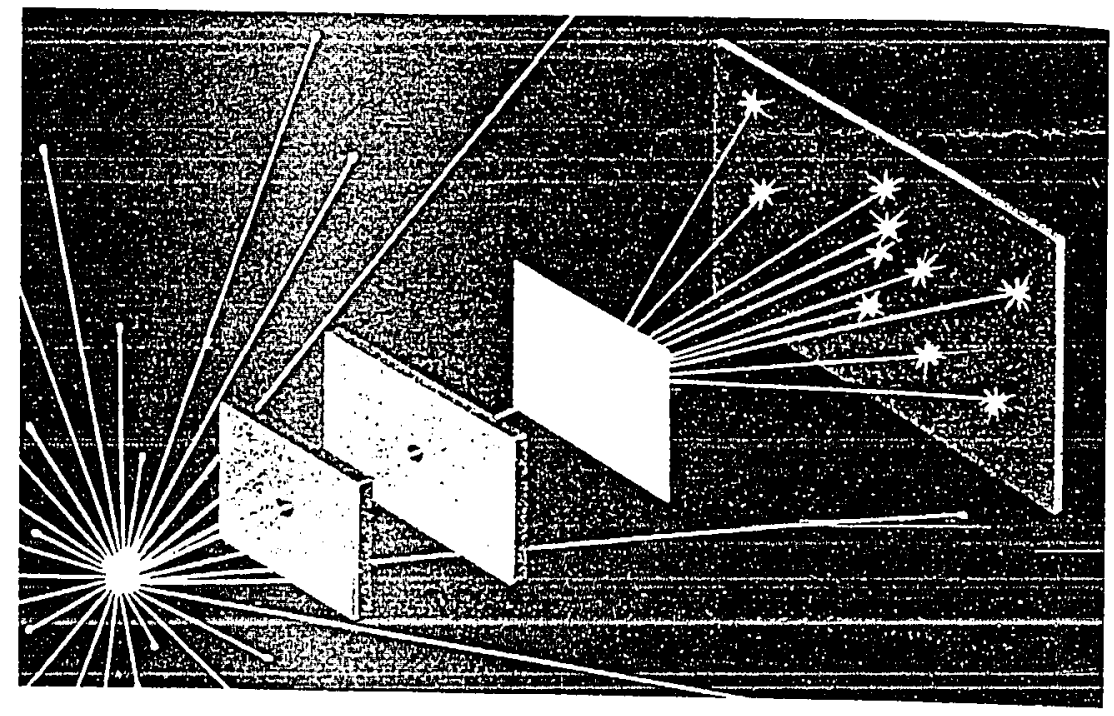

Figure 1. Alpha particle scattering. Alpha particles scattered by a thin metal foil are detected when they strike a metal plate coated with zinc sulfide.(2)

When Rutherford's team examined the results of their experiments they determined that the number of $\alpha$-particles scattered through large angles could not be explained by a uniform distribution of charge in the atom as theorized by J.J. Thomson. Instead, they concluded that most of the mass and charge of an atom must be concentrated in the 
center of the atom, which Rutherford named the nucleus. Hence, the use of zinc sulfide helped physicists discover one of the important physical results in the 20th century. Zinc sulfide has applications in the field of biology where it has been used for marking autoradiograms. Donald Seto, et al.(3) at California Institute of Technology used suspensions of $\mathrm{ZnS}$ in water or glycerol to detect light emission. When the suspension is exposed to an incandescent light source, it will emit visible light in the green-yellow range. It is this property that makes $\mathrm{zns}$ suitable for applications such as molecular cloning techniques, radioactive nucleotide sequencing and nonradiative detecting systems such as chemiluminescent probes which may require orientation and identification markings.

The phosphorescent properties of $\mathrm{zns}$ also make it an excellent choice for display applications. Activated $\mathrm{ZnS}$ has been used for years in cathode ray tubes in televisions, oscilloscopes, and electron microscopes. In CRT's, the phosphorescent properties of zinc sulfide again come into play. Electrons are excited into the conduction band as before. Impurities are engineered into the $z$ inc sulfide to cause traps resulting in photon emission with wavelengths corresponding to green, blue and red. 
Zinc sulfide also displays electroluminescent properties. Electroluminescence is defined as the emission of visible light by a $p-n$ junction across which a forwardbiased voltage is applied. Electroluminescent devices are commonly manufactured using $\mathrm{zns}$ thin film layers. In the past, these films have been grown by atomic layer epitaxy (ALE), molecular beam epitaxy (MBE), and metal organic chemical vapor deposition (MOCVD).

\section{Deposition Techniques}

Deposition of thin film ZnS layers can be carried out by several techniques. Along with MOCVD, two other techniques coming into wider use are atomic layer epitaxy and molecular beam epitaxy.

Atomic Layer Epitaxy Also known as ALE, was primarily developed for the deposition of compound semiconductors, either III/V or II/VI compounds. The characteristic feature of ALE is the sequential alternating saturation of each layer grown of the compound of interest. For instance, in the growth of $\mathrm{ZnS}$ by $\mathrm{ALE}$, first a layer of $\mathrm{Zn}$ would be allowed to saturate on the surface, growth would be suspended, then a layer of $S$ would be allowed to saturate on top of the layer of $\mathrm{zn}$, growth would be suspended, then the cycle would repeat until the desired thickness is reached. In most cases, each growth step 
constitutes less than a full monolayer, bringing up the importance of surface reconstruction during each step of the deposition. (5) A representation of ALE is shown in Figure 2 .

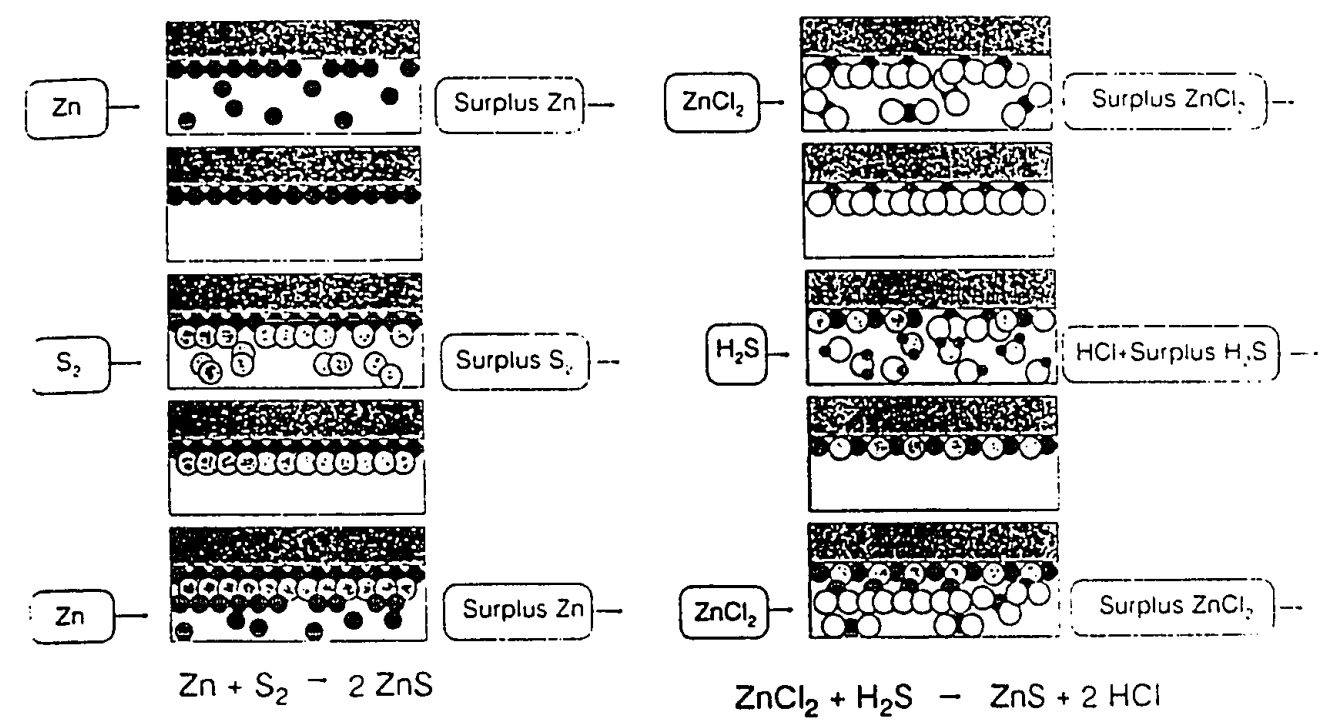

Figure 2. Atomic Layer Epitaxy of zns. sequences of ALE process for zns using (a) elemental reactants (exposure to zine vapor, chemisorption of zinc monolayer, purge of zinc surplus, exposure to $s_{2}$ vapor, chemisorption of sulfur, purge of $s_{2}$ surplus, exposure to zinc vapor etc.) and (b) compound reactants (exposure to $\mathrm{ZnCl}_{2}$ vapor, chemisorption of $\mathrm{znCl}_{2}$, purge of $\mathrm{znCl}_{2}$ surplus, exposure to $\mathrm{H}_{2} \mathrm{~s}$, exchange reaction resulting in solid $\mathrm{zns}$ and $\mathrm{HCl}$, purge of $\mathrm{HCl}$ and surplus of $\mathrm{H}_{2} 8$, exposure to $\mathrm{ZnCl}_{2}$ vapor, etc.). (5)

One of the main uses of ALE is in the deposition of Zns layers for TFEL's. A cross section of this film is 
likely to have columnar growth arising from 2-dimensional nucleation, rather than columnar growth resulting from "point nucleus" growth. In other words, defects originating from the original surface at the onset of ALE do not grow and expand as they would in point nucleus growth. Columnar growth is a common feature seen in polycrystalline layers of $\mathrm{zns}$. It is more desirable to have columns with 2-dimensional origination since they don't expand and overlap, further reducing the crystallinity of the layers.

ALE equipment is of two types: High vacuum systems similar to an MBE chamber and CVD-type systems capable of growing at a range of pressures. The high vacuum type of systems have an advantage in being better fitted for insitu measurements, while the CVD-type systems can more easily be scaled up to industrial applications.

Molecular Beam Epitaxy MBE has been utilized by Yoshikawa, et al.(6) in their development of single-crystal ZnS and znse for use as blue light emitting diodes. They used DMZn and either $\mathrm{H}_{2} \mathrm{~S}$ or $\mathrm{H}_{2} \mathrm{Se}$ as reactants. One of the advantages of MBE is the long mean free path between collisions as a result of the high vacuum of the process. This virtually eliminates pre-reaction of the chemical species. A schematic of a typical MBE apparatus is shown in Figure 3. 
other methods, such as sputtering and vacuum

deposition can be implemented much less expensively, but

films of good crystallinity are much harder to produce.



Figure 3. Simplified schematic of an MBE Reactor (7). 


\section{MOCVD of zinc sulfide}

MOCVD has become an increasingly important growth technique over the past 20 years and has expancied in use from primarily III/V work to II/VI work. It is expected that in the future MOCVD will become important in the areas of superconductors and high dielectric insulators.

Thin film growth by MOCVD has both advantages and disadvantages. It is very versatile and easily scaled up, but it can also be very expensive. Large scale production reactors, capable of handling many wafers at a time, can cost upwards of a million dollars. MOcVD reactors use both liquid and gaseous reactant sources, and much of the high cost of running an MOCVD reactor is due to the safety systems, temperature controlling systems and monitoring systems needed to safely achieve high quality thin films. Reactant sources for MOCVD are of two varieties: A gaseous source, such as 18 dimethylzinc (DMZn) in helium; or a liquid source, such as pure liquid DMZn, through which a carrier gas is bubbled.

A schematic of an entirely gaseous source MocvD apparatus is shown in Figure 4. 


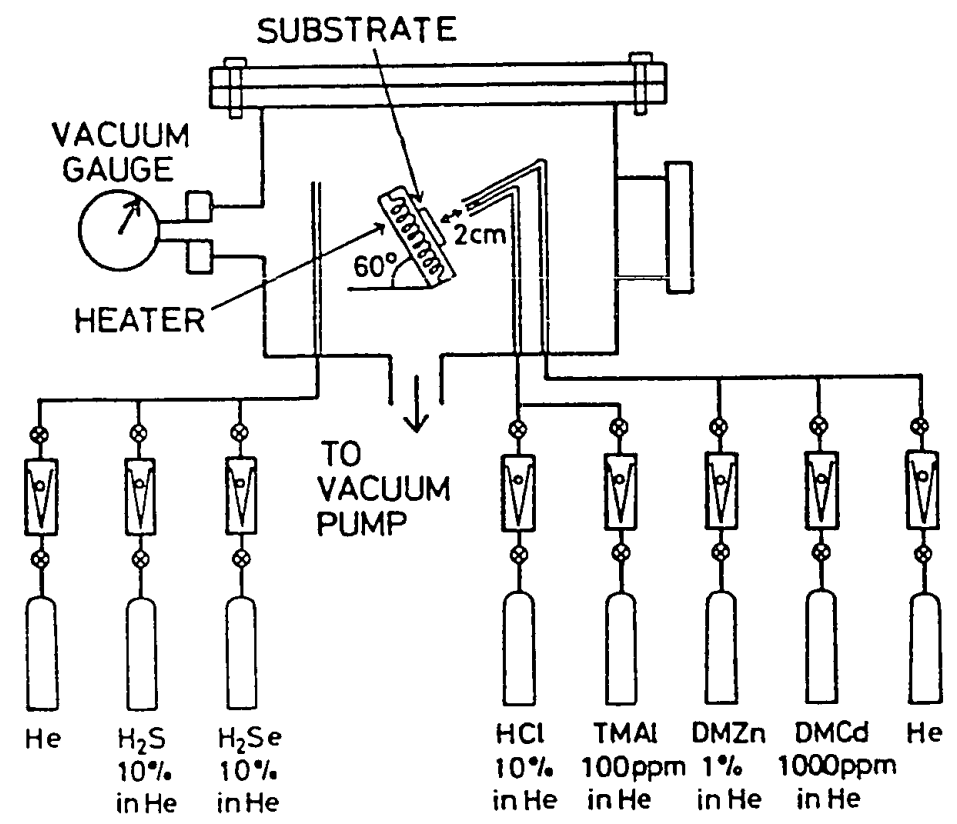

Figure 4. Gaseous source MOCVD Reactor. Bchematic diagram of an entirely gaseous source MoCVD reactor. (8)

In this diagram, the essential parts of the MOCVD apparatus are described:

Gaseous $1 \%$ DMZn in helium and $10 \%$ hydrogen sulfide $\left(\mathrm{H}_{2} \mathrm{~S}\right)$ in helium travel toward the reactor in separate gas lines. The $\mathrm{H}_{2} \mathrm{~S}$ line terminates inside the chamber so as to provide good mixing throughout, while the DMzn line terminates just above and pointing directly towards the susceptor. The susceptor temperature is automatically controlled by a thermocouple placed in the susceptor. The reactants travel across the susceptor where they increase in temperature and deposit onto the susceptor and the 
substrate which is placed on the susceptor. The carrier gas along with the reacted species are exhausted out the bottom of the reactor.

The second type of MOCVD apparatus, containing one or more liquid organometallic sources is shown in Figure 5.

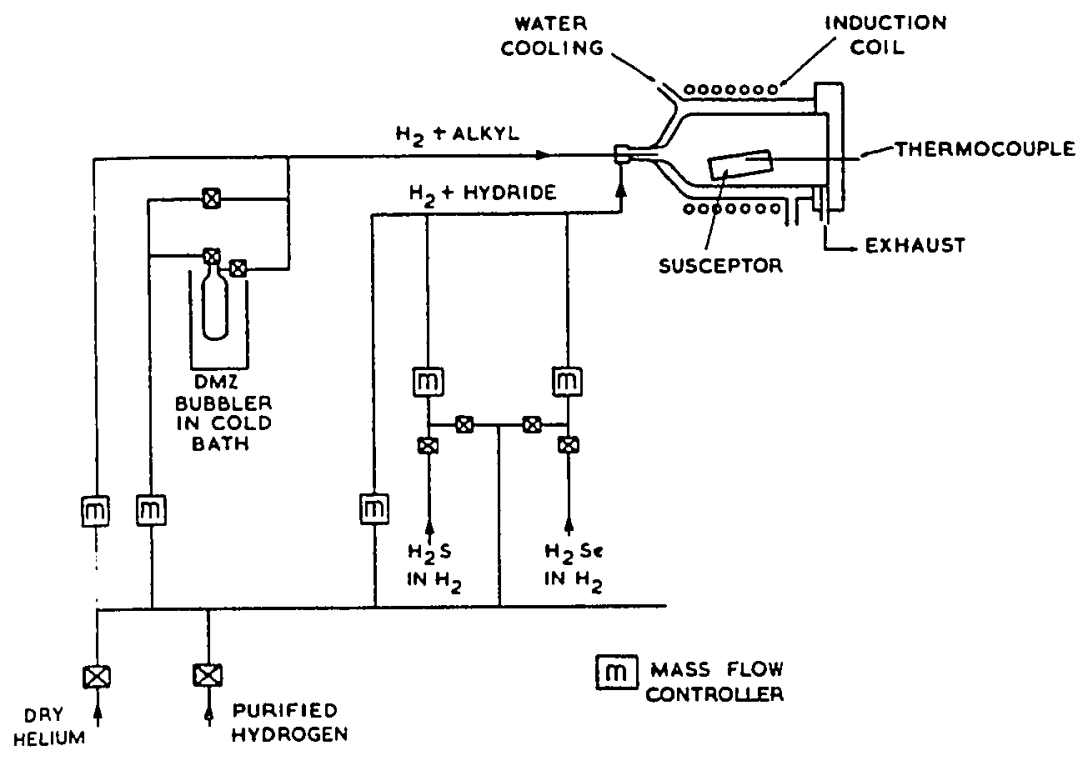

Figure 5. Gaseous and Liquid source MOCVD reactor.

Schematic diagram of HOCVD reactor containing one liquid organometallic source.(9)

In this setup, pure helium is bubbled through a temperature-controlled DMZn bubbler, saturates with DMZn, and then travels towards the reactor inlet. The gaseous species travel toward the reactor inlet in a separate gas line and meet at the upstream edge of the reactor inlet. 
The reactants flow over the susceptor, heat up and deposit onto the substrate.

In general, in MOCVD of II/VI semiconductor thin films, the group II sources, like zinc and cadmium, are kept separate from the group VI sources, like sulfur, selenium and tellurium, until they reach the reactor inlet. This is to avoid premature reactions which could cause condensation on the plumbing lines leading to the reactor. There are also several types of susceptor geometries in use as shown in Figure 6. Typically, horizontal- and pedestal-type geometries are capable of holding one or two wafers and are used primarily for research and development applications, while the large scale barrel- and pancake-type geometries are capable of holding up to 24 wafers. 


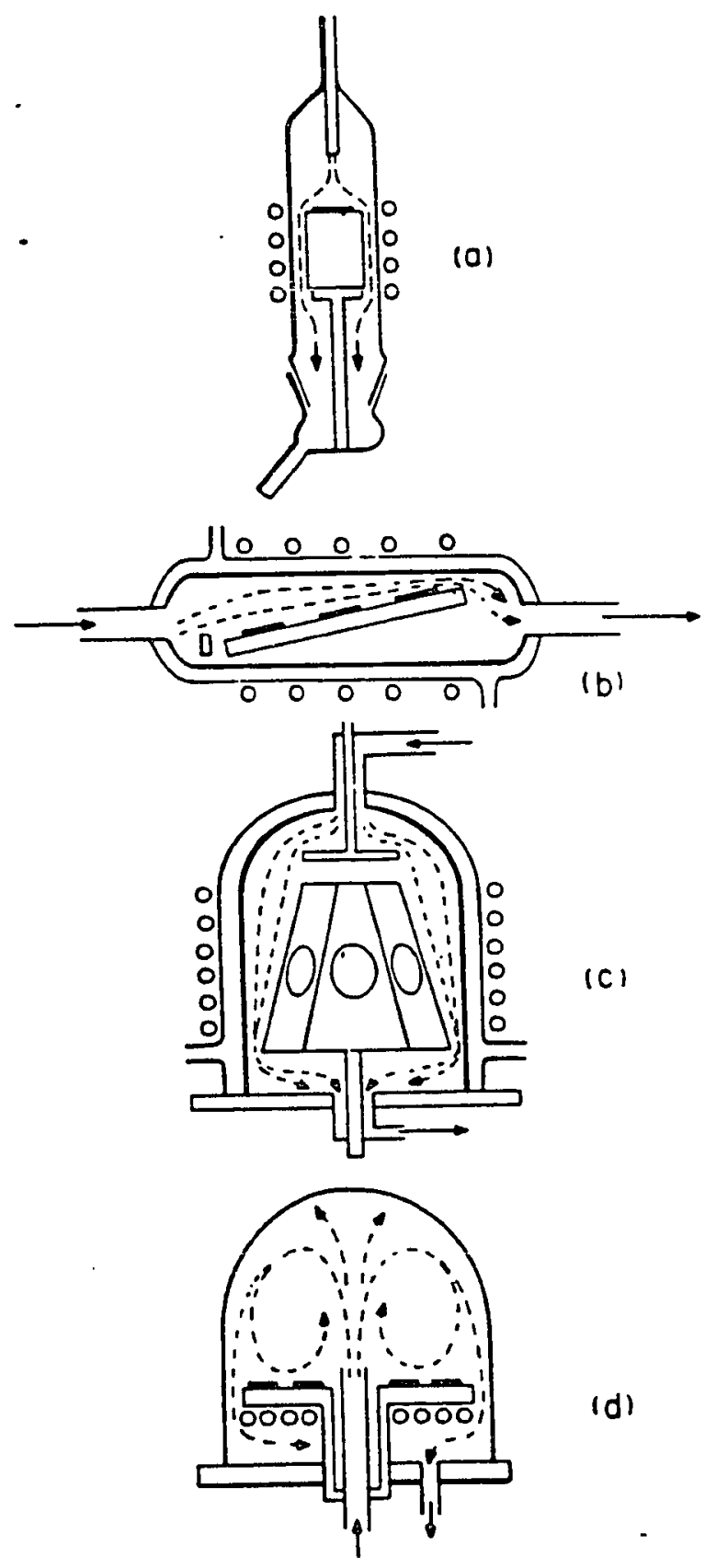

Figure 6. Susceptor Geometries Used in MOCVD. schematic representation of susceptor geometries used in MOCVD: (a) pedestal, (b) horizontal, (c) barrel, and (d) pancake.(10) 


\section{Sources Used in MOCVD of zns}

As varied as the applications for $\mathrm{zns}$ are, and as varied as the types of deposition and doping techniques used in the growth of $\mathrm{ZnS}$ layers, so too are the precursor chemicals used in the production of zns layers.

zn sources. By far the most commonly used zinc compounds are DMZn and DEZn. They both are pyrophoric substances in their pure forms.

Wright and cockayne have reported work using liquid DMZn(12), as have Hirabayashi and Kogure(11), while Fujita, et al.(12) have reported using both DEZn and DMZn liquids in their work. In these three cases $\mathrm{H}_{2}$ gas was used as the carrier to transport the $z$ inc sources to the reaction chamber. Yoshikawa(13) also reports using DMZn but he chose a system using all gaseous sources of the chemical of interest mixed with helium, and helium as the ballast gas.

In cases where pre-reaction of the $\mathrm{Zn}$ source with $\mathrm{H}_{2} \mathrm{~S}$ is of concern, work has been reported using the chelating ligands of zinc called 1,4-dioxan and 1,4-thioxan. (14) Use of these adducts in place of DMZn or DEZn prevented prereaction at low temperatures, but did not push up the susceptor temperature needed for successful growth. The structure of these compounds is shown in Figure 7 . 

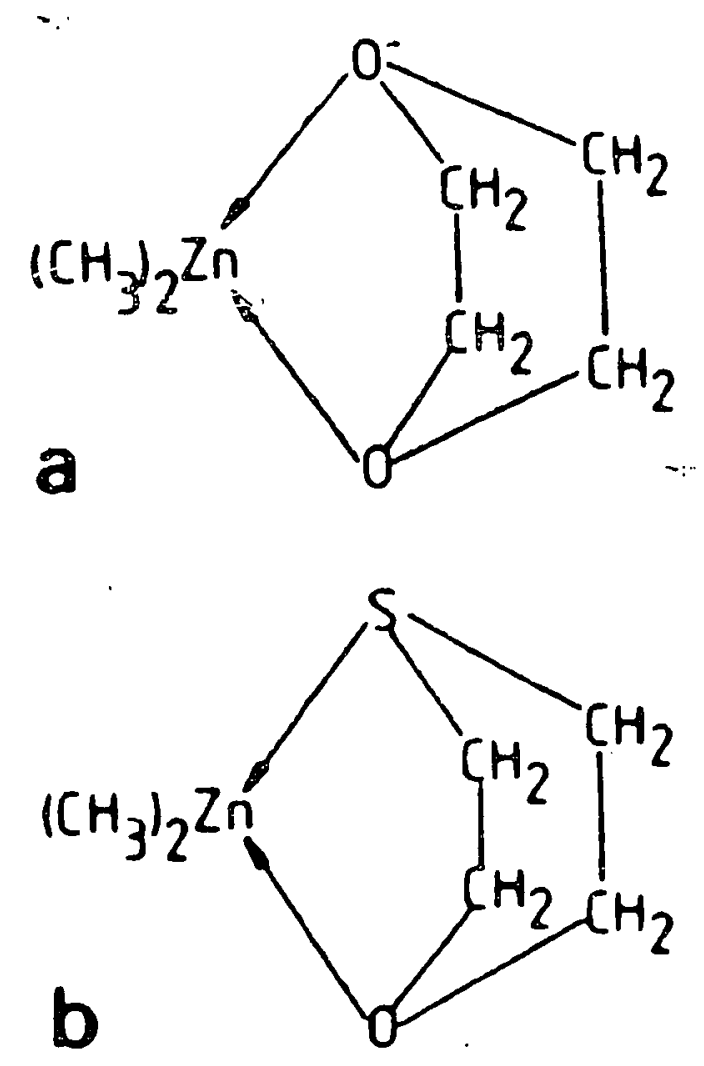

\section{Figure 7. Alternative zinc sources for $\mathrm{zns}$ Growth. \\ Dimethylzinc adducts of (a) $1,4-d i o s a n$ (MP $66^{\circ} \mathrm{C}$ ) and (b) 1,4 -thioxan (MP $23^{\circ} \mathrm{C}$ ). (14)}

sulfur sources. Sulfur sources utilized have been

quite varied over the last ten years of work in this field. Hydrogen sulfide has been the chemical of choice when low growth temperature was important. Yoshikawa, et al.(13) cites many reasons for his desire to use $\mathrm{H}_{2} \mathrm{~S}$. Among them are the problems inherent in using a liquid source, such as:

1) possible desaturation of the bubbled species, 
2) temperature fluctuation which affects the vapor pressure of the source,

3) inaccurate estimation of the amount of material left in a bubbler, and

4) the many valves and fittings, temperature controllers, etc. that may be needed with the use of liquid sources.

The use of liquid sulfur sources, though, has several distinct advantages over the use of $\mathrm{H}_{2} \mathrm{~S}$.

Use of carbon disulfide was chosen by Takata, et al., (15) because it is less expensive than other liquid sources in use, it is easier to handle than a toxic gas like $\mathrm{H}_{2} \mathrm{~S}$, and the problem of premature reaction is eliminated. Hirabayashi and Kozawaguchi(16) reported using diethylsulfur. Its disadvantages are that it is expensive, and it requires a high growth temperature. They were able to take care of the high growth temperature problem by using photo-assisted deposition, which allowed them to reduce the growth temperature from $500^{\circ} \mathrm{C}$ to $400^{\circ} \mathrm{C}$ by irradiation, as shown in Figure 8.

Finally, the use of heterocyclic compounds has been studied in some detail by Jones, et al.(14) They experimented with heterocyclic compounds and found that they eliminated pre-reaction of the zinc compound and the sulfur compound but the price they paid was a higher growth 
temperature. The compounds they used are shown in Figure 9.

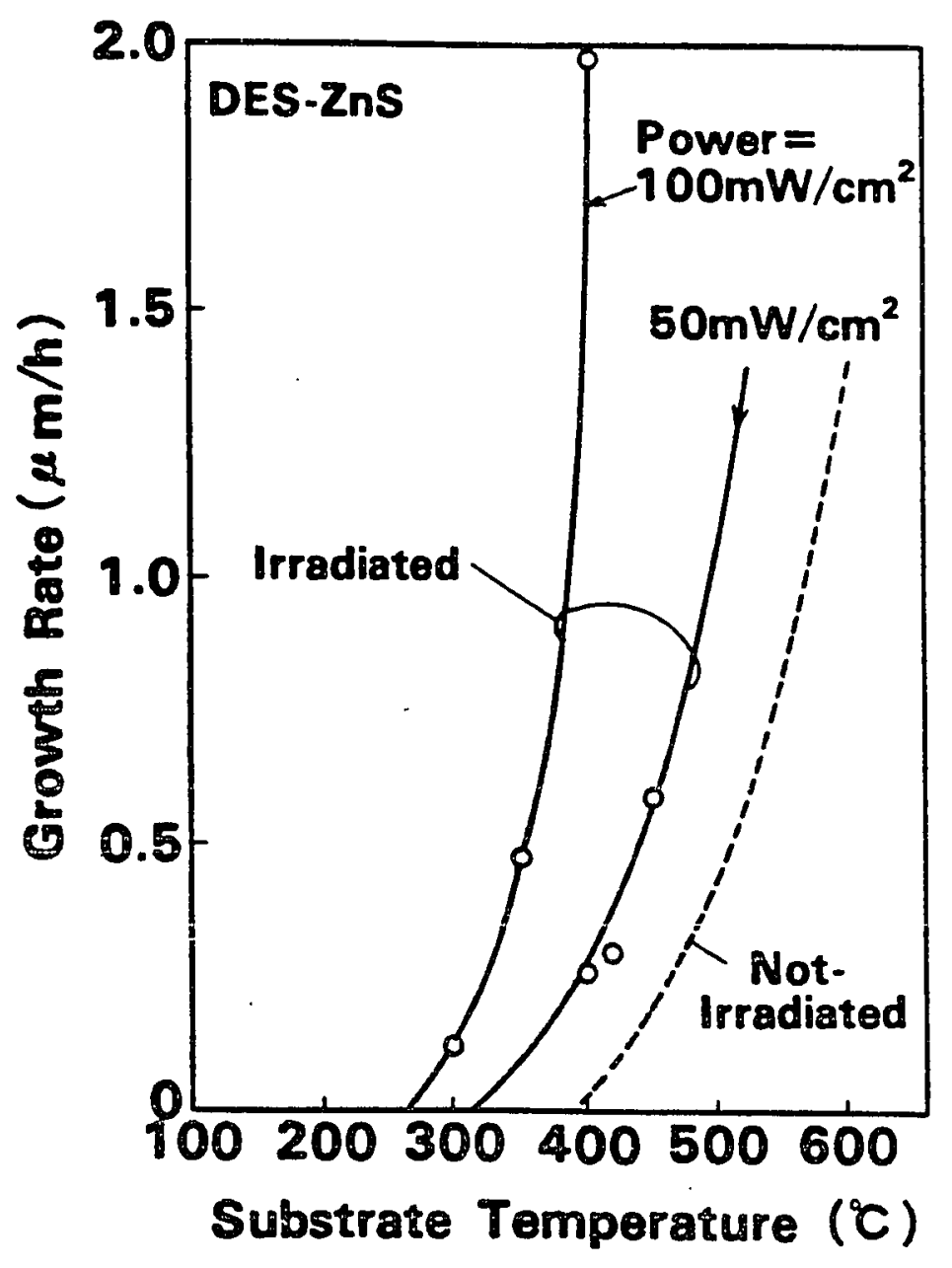

Figure 8. Photo-Assisted MocVD. Growth temperature dependence of growth rate for zns:Mn film prepared with and without radiation. (16) 

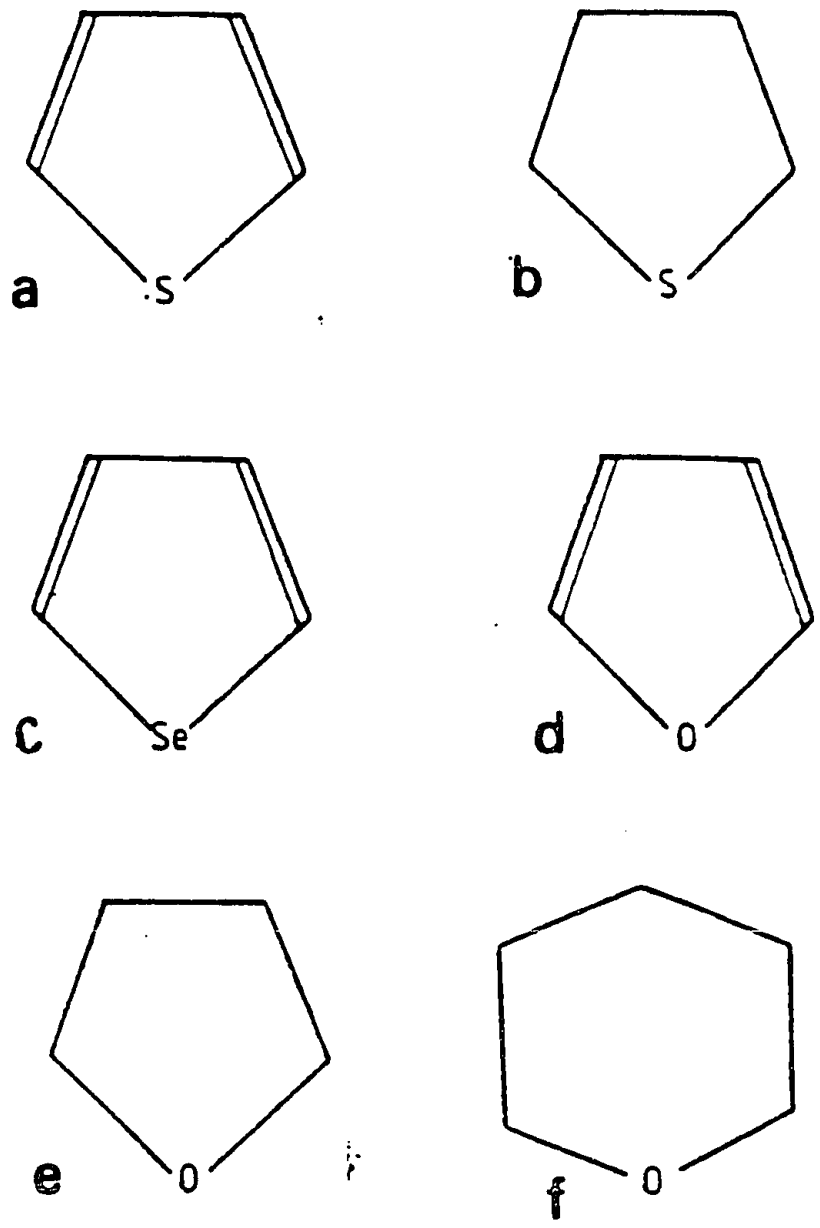

Figure 9. Alternative sulfur sources for $\mathrm{zns}$ Growth.

Feterocycile compounds used in the growth of $\mathrm{zns}$, znse, and $\mathrm{znO}$ : (a) thiophene $\left(\mathrm{C}_{4} \mathrm{H}_{4} \mathrm{~s}\right)$ : (b) tetrahydrothiophene $\left(\mathrm{C}_{4} \mathrm{H}_{8} \mathrm{~S}\right) ;$ (C) selenophene $\left(\mathrm{C}_{4} \mathrm{H}_{4} \mathrm{Se}\right)$; (d) furan $\left(\mathrm{C}_{4} \mathrm{~B}_{4} \mathrm{O}\right)$; (e) tetrahydrofuran $\left(\mathrm{C}_{4} \mathrm{H}_{8} \mathrm{~s}\right):$ (f) tetrabydropyran $\left(\mathrm{C}_{5} \mathrm{H}_{10} \mathrm{O}\right)$.(14) 


\section{safety of Precursors Used in Mocvd of zis.}

Another factor touched upon earlier is the safety concerns of the chemicals chosen. Mixtures of DMZn in $\mathrm{H}_{2}$ are classified as a flammable gas while mixtures of DMZn in helium are classified as a non-flammable gas. All of these mixtures should be considered to be simple asphyxiants.

DMZn and DEZn in their pure forms in liquid bubblers are classified as pyrophoric liquids. They spontaneously ignite in air and react violently in water. When pure DMZn reacts with air, zinc oxide fumes result which, when inhaled, can alter blood proteins leading to a hyperthermic reaction(17).

Hydrogen sulfide is classified as a flammable compressed gas. It is a toxic gas with a very distinct rotten egg odor. The lowest lethal concentration published for humans is $600 \mathrm{ppm}$ for 30 minutes. $(17,18)$ Carbon disulfide $\left(\mathrm{CS}_{2}\right)$, diethyI sulfur (DES), and thiophene (or thiofuran) are all available in liquid form and do not pose the toxic inhalation threat that $\mathrm{H}_{2} \mathrm{~S}$ does.

The lowest lethal concentration published for $\mathrm{CS}_{2}$ is $4000 \mathrm{ppm}$ for 30 minutes. $\mathrm{CS}_{2}$ is also used as an insecticide and when inhaled has an anesthetic effect resembling alcoholic intoxication. It is stable in air up to $194^{\circ} \mathrm{F}\left(90^{\circ} \mathrm{C}\right) \cdot(19)$ 
DES has a characteristic garlic-like odor. No details are available on the toxicity of DES, but it is listed as "probably high." No details are available on fire hazard. (20)

Thiophene is a clear colorless liquid that is stable in air. The lowest published lethal concentration is 8700 ppm, for mice. The toxic summary for thiophene is listed as "moderate" via inhalation routes and "high" via intraperitoneal (or digestive) routes. (21) so if you smell it, be sure not to swallow.

\section{Summary of MOCVD Sources for zns}

The available physical data for sources used in growth of $\mathrm{znS}$ is summarized in Table 1. In general, liquid $\mathrm{zn}$ sources are chosen when gaseous species are undesirable due to safety concerns. The advantage to gaseous $\mathrm{zn}$ sources are that they can be metered more precisely since they are reiativeiy insensitive to ambient temperature, etc. In the case of sulfur sources, $\mathrm{H}_{2} \mathrm{~S}$ is the most commonly used, but is a gaseous, highly toxic species that must be carefully managed. There are several desirable liquid species. DES, though, is expensive and requires high growth temperatures. $\mathrm{CS}_{2}$ is less toxic and can be used in the $400^{\circ} \mathrm{C}$ growth temperature range. 
Thiophene is less toxic than $\mathrm{CS}_{2}$ but, according to Jones, et al.,(14) requires growth temperatures around $450^{\circ} \mathrm{C}$ to $500^{\circ} \mathrm{C}$.

In this work, DMZn in He is used as the zinc source and thiophene Iiquid with He as the carrier gas is used as the sulfur source.

\begin{tabular}{|c|c|c|c|c|c|}
\hline \multirow[b]{2}{*}{ Compound } & & $\begin{array}{r}\text { Physi } \\
\text { Commonly } \\
\text { Growt }\end{array}$ & $\begin{array}{l}\text { Table } \\
\text { al Data } \\
\text { Ised Sor } \\
\text { of zinc }\end{array}$ & $\begin{array}{l}\text { the } \\
\text { in the } \\
\text { Ifide }\end{array}$ & \multirow[b]{2}{*}{ Ref. } \\
\hline & $\underline{\text { MW }}$ & $\begin{array}{l}\text { s.p. } \\
\left.\dot{(}^{\circ} \mathrm{C}\right)\end{array}$ & $\begin{array}{l}\text { b.p. } \\
(\cdot \mathrm{c})\end{array}$ & Forms Available & \\
\hline DEZn & 123.49 & -28.0 & 118.0 & liq., gas mixture & $(21)$ \\
\hline $\mathrm{DMZn}$ & 95.44 & -42.2 & 46.0 & liq., gas mixture & (22) \\
\hline $\mathrm{H}_{2} \mathrm{~S}$ & 34.08 & -85.5 & -60.7 & gas, gas mixture & (17) \\
\hline $\mathrm{CS}_{2}$ & 76.14 & -111.5 & 46.2 & liquid & (22) \\
\hline DES & 80.09 & -103.8 & 92.1 & liquid & $(22)$ \\
\hline $\mathrm{C}_{4} \mathrm{H}_{4} \mathrm{~S}$ & 84.14 & -38.2 & 84.2 & liquid & (22) \\
\hline
\end{tabular}

\section{Rinetics of Reactions by MocvD}

An important factor in MOCVD growth is the dependence of growth rates on various parameters involved. Previous work has determined that as DMZn flow is 
increased, the growth rate is increased. But in assessing the effect of DMZn flow rate, it is important to compensate for the changing carrier gas flow rate by altering the ballast gas flow rate so there will be no net change of flow rate into the reactor. With this pre-condition, the growth rate has been found by Yoshikawa(8) to be directly related to the DMZn flow.

The temperature contribution on growth rate is also important to consider. In this case, it turns out that growth rate is directly related to temperature up to an optimum temperature, and above the optimum temperature, the growth rate is inversely related to the temperature. The reason for this is as follows: At low temperatures, it is the activation energy required for the deposition reaction that limits the growth rate. However, above the "optimum" temperature, desorption of reactants from the substrate begins to dominate the activation energy effect on growth rate, and if temperature is increased further, the growth rate will decline.

The dependence of growth rate on reactor pressure, holding flow rates fixed, was also studied by Yoshikawa(8). They found that as the reactor pressure increases, the growth rate increases as well. But, at some saturation value, the effect on growth rate becomes negligible, and higher pressures will not change the growth rate. 


\section{Fabrication Techniques of zinc sulfide Devices}

Greenberg, et al., grew epitaxial layers of $\mathrm{zns}$ on sapphire.(4) They used CVD with sources of high purity ZnS and $\mathrm{H}_{2}$ as the carrier gas. The growth temperatures they used ranged from $745^{\circ} \mathrm{C}$ to $870^{\circ} \mathrm{C}$ with a growth rate of 2.4 to $3.5 \mu \mathrm{m} / \mathrm{hr}$ to achieve final thicknesses of about $15 \mu \mathrm{m}$. Hirabayashi and Kogure(23) prepared thin film electroluminescent devices using the metal-insulatorsemiconductor (MIS) structure. They began with a glass substrate covered with indium-tin-oxide (ITO), followed by a manganese-doped ZnS (ZnS:Mn) phosphor layer. Next, $0.35 \mu \mathrm{m}$ of $\mathrm{Sm}_{2} \mathrm{O}_{3}$ was deposited by E-beam evaporation, and finally an aluminum electrode was evaporated on top. In their deposition of the zns layer they used dimethylzinc (DMZn) in a bubbler kept at $-10^{\circ} \mathrm{C}$ with $\mathrm{H}_{2}$ as the carrier gas. The sulfur source they chose was 5\% hydrogen sulfide $\left(\mathrm{H}_{2} \mathrm{~S}\right)$ in hydrogen $\left(\mathrm{H}_{2}\right)$ gas. Growth was carried out at $300^{\circ} \mathrm{C}$ and at low pressure. The luminescence center Mn was introduced into the $\mathrm{z}$ s layer by thermal diffusion. This was chosen as an improvement over the doping method using tricarbonyl-methyl-cyclopentadienyl-Mn (TCM) because this needed to be carried out at $\sim 450^{\circ} \mathrm{C}$, leading to poor crystallinity of the $\mathrm{ZnS}$ layer, and reaction between the Zns film and the ITO layer. The zns layer grown was 
polycrystalline in nature, with individual grains of about $3500 \AA$ in diameter.

Another approach was chosen by Takata, et al.,(15) who also worked on TFEL's. They used $\mathrm{H}_{2}$ as a carrier gas bubbled through diethylzinc (DEZn) at $12^{\circ} \mathrm{C}$ and bubbled through carbon disulfide $\left(\mathrm{Cs}_{2}\right)$ at $-5^{\circ} \mathrm{C}$. Growth temperature was varied from $200^{\circ} \mathrm{C}$ to $425^{\circ} \mathrm{C}$, and was found to be optimum between $325^{\circ} \mathrm{C}$ and $425^{\circ} \mathrm{C}$. Reactor pressure during growth ranged from 160 to 360 torr. This team was concerned about pre-reaction between the sources so they experimented with the $\mathrm{CS}_{2}$ alone. Conducting a run while supplying only $\mathrm{CS}_{2}+$ $\mathrm{H}_{2}$ into the reaction chamber, they observed no deposition below $425^{\circ} \mathrm{C}$. Then, supplying both $\mathrm{Cs}_{2}$ and DEzn with their respective carrier gases, they observed no $\mathrm{Zns}$ deposit below $200^{\circ} \mathrm{C}$. They found that with the growth temperature held at $400^{\circ} \mathrm{C}$, the growth rate was linearly related to the $\mathrm{S} / \mathrm{Zn}$ molar influx ratio. Also, they found that with a fixed $\mathrm{S} / \mathrm{Zn}$ molar ratio of 20 , that the growth rate was directly related to growth temperature up to $400^{\circ} \mathrm{C}$, and that growth rate was inversely related to growth temperature above $400^{\circ} \mathrm{C}$.

MOCVD-grown TFEL's using $\mathrm{CS}_{2}$ have also been reported by Minami, et al.,(24) as a continuation of their work cited above.(15) They used a barium titanate (BaTiO ${ }_{3}$ ) ceramic sheet as both the insulating layer and substrate. 
On top of this they deposited $\mathrm{znS}$ by MOCVD using DEZn and $\mathrm{CS}_{2}$ at a S/Zn molar ratio of 20 . They used growth temperatures ranging from $275^{\circ} \mathrm{C}$ to $400^{\circ} \mathrm{C}$. Manganese for the luminescent center was thermally diffused into $\mathrm{zns}$ at $600^{\circ} \mathrm{C}$ in an argon atmosphere. The top electrode of aluminum-doped $z$ inc oxide was deposited using radio frequency (rf) magnetron sputtering. Finally, an Al layer was evaporated onto the bottom of the ceramic sheet to serve as the back electrode.

Yet another approach to fabrication of TFEL devices is provided by Hirabayashi, et al.,(16) who fabricated their devices using $\mathrm{ZnS}$ thin film layers obtained by photoassisted MOCVD using dimethylzinc (DMZn) and diethyl sulfur (DES). Without photo-assisted growth, they reported a minimum growth temperature of $400^{\circ} \mathrm{C}$, while with photoassisted growth, they were able to reduce the minimum growth temperature to $300^{\circ} \mathrm{C}$. The effect of photo-assisted deposition had two competing influences. On one hand, they were able to lower growth temperature, but on the other hand, the luminance of the photo-assisted prepared layers was lower due to irradiation damage causing many sulfur vacancies.

Finally, Migita, et al.(25) experimented with different Mn sources for doping the ZnS layer. MOCVD of ZnS was carried out using DEZn and $\mathrm{H}_{2} \mathrm{~S}$ and three different 
Mn dopant sources: di-a-cyclopentadienyl manganese (CPM), bi-methylcyclopentadienyl manganese (BCPM), and tricarbonyl methylcyclopentadienyl manganese (TCM). In these studies, they found high efficiency and high luminance using either CPM or BCPM, but very low values when TCM was used. Other variables investigated were growth temperature ranging from $280^{\circ} \mathrm{C}$ to $350^{\circ} \mathrm{C}$ and reactor pressure ranging from 0.6 torr to 2.0 torr. 


\section{Apparatus}

The MOCVD reactor used in this work is installed in the Materials Engineering Department at San Jose State University. It was first built by Marc Jensen(26) and modified by Hoa Do(27). Work has also been done using this system by Dennis Ramos(28), Hamid Kashani(29), Rex Chuang(30), and Richard Patten(31). A schematic of this reactor is shown in Figure 10 .

The reactor is designed for low pressure work, in the range of 0.5 to 10 torr. It is capable of using either liquid or gaseous sources of zinc and sulfur. Upon reaching the reactor, the sulfur source is injected at the end of the reactor tube and disperses throughout the chamber. The zinc source has two paths into the reaction chamber: (1) bypass, where the zinc flows outside the quartz liner in which the susceptor and substrate sit. Flowing the zinc through the bypass valve is useful for stabilizing flows and temperature before the onset of deposition, and (2) the inject valve, pointing directly at the susceptor where the zinc flows during the actual deposition of $\mathrm{ZnS}$. To initiate and terminate growth, the zinc valve is toggled between the two states. Heating of the substrate is accomplished by two quartz lamps situated 
on the bottom of the susceptor with output controlled by a VARIAC potentiometer.

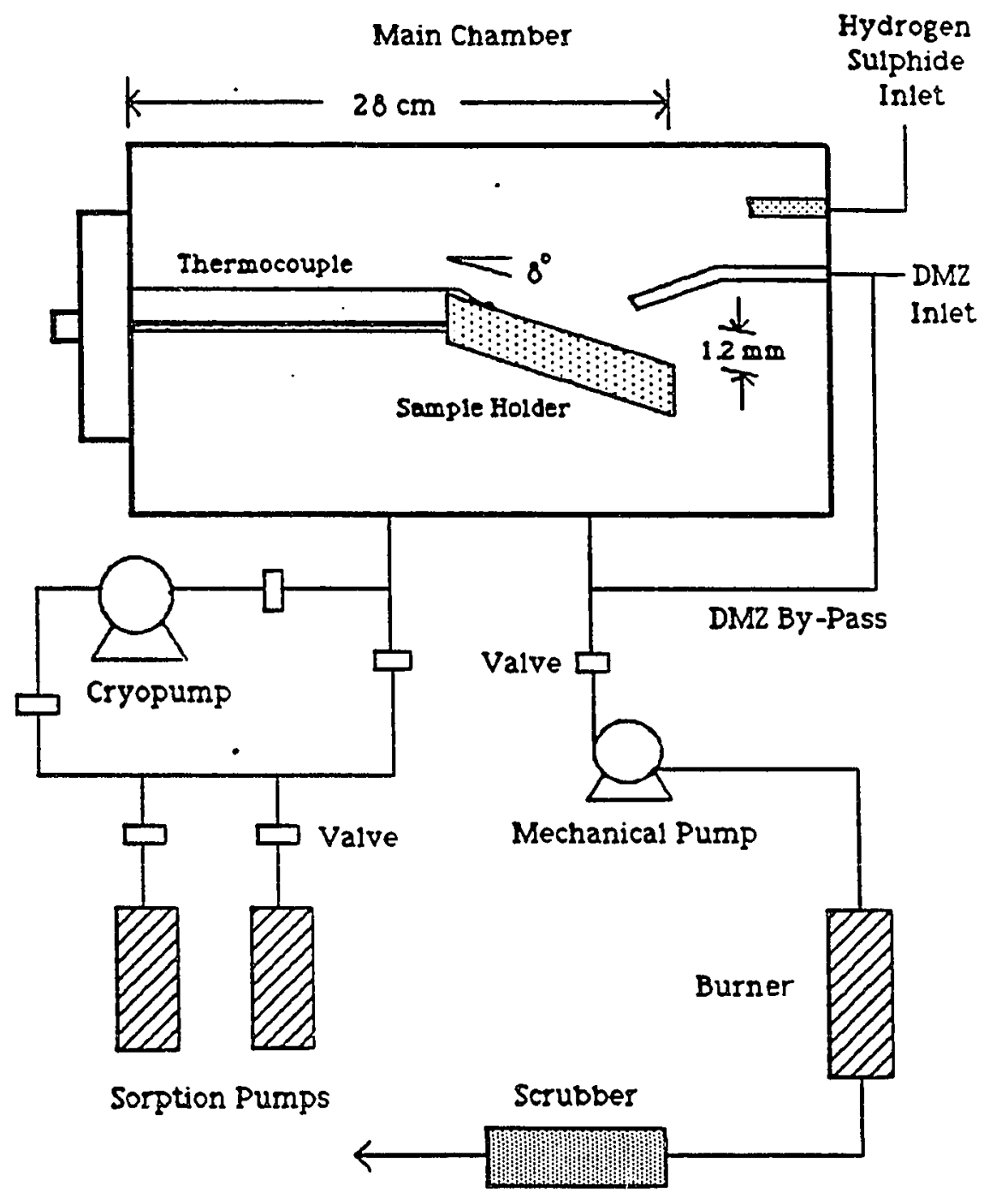

Figure 10. MocVD Apparatus. schematic of Low Pressure MOCVD Apparatus Used in This Work(30). 
Flow rates are controlled by needle valves located in the gas lines leading to the reactor and reactor pressure is set by a hand-operated vacuum valve which must be very carefully set to achieve the desired pressure. Temperature is sensed by two thermocouples, one situated above the susceptor, just behind the substrate, and the other situated along the underside of the susceptor, where the two heating lamps are located.

The mechanical pump used to exhaust the reactor is a 2-stage rotary vane pump with a capacity of $473 \mathrm{lit} / \mathrm{min}$, ultimate pressure of $5 \times 10^{-4}$ torr.

A burner unit is located downstream from the pump to burn the exhaust products. This urit is kept at $970^{\circ} \mathrm{C}$ to $1000^{\circ} \mathrm{C}$ during the runs. Inside the burner unit is some baffling to slow down the exhaust gases and ensure they are completely burned before they move into the scrubber.

The scrubber is a cylindrical stainless steel tank with two spray nozzles diametrically opposed and situated inside the tank at the top, aiming down at about a 45 degree angle. The exhaust gases enter the scrubber at the bottom and are sprayed down by the two nozzles. The heavier products are washed down the drain of the scrubber while the lighter products exit at the top of the scrubber into the building vent duct. 
The entire gas handling portion of the reactor is located underneath a fume hood to minimize release of any toxic material into the room in the event of a leak.

The reaction that takes place at the susceptor is dependent on the reacting species being used. For example, if the species are DMZn and $\mathrm{H}_{2} \mathrm{~S}$, the mechanism is fairly well understood and the deposition reaction has been found to be:

$$
\begin{array}{r}
\left(\mathrm{CH}_{3}\right)_{2} \mathrm{Zn}+\mathrm{H}_{2} \mathrm{~S}(\mathrm{~g})-\cdots \mathrm{ZnS}(\mathrm{s})+2 \mathrm{CH}_{4}(\mathrm{~g}) \\
\text { (methane) }
\end{array}
$$

No mechanisms were found for the system of DMZn and thiophene $\left(\mathrm{C}_{4} \mathrm{H}_{4} \mathrm{~S}\right)$, but one possibility is:

$$
\begin{aligned}
&\left(\mathrm{CH}_{3}\right)_{2} \mathrm{Zn}+\mathrm{C}_{4} \mathrm{H}_{4} \mathrm{~S} \quad \longrightarrow-\mathrm{ZnS}(\mathrm{s})+\mathrm{C}_{6} \mathrm{H}_{10}(\mathrm{~g}) \\
& \text { (cyclohexene) }
\end{aligned}
$$

For this work, the zinc source used was $1 \%$ DMZn in helium and was metered into the reactor through a Matheson Model 603 rotameter. Both $\mathrm{H}_{2} \mathrm{~S}$ and thiophene were used for this work. $10 \% \mathrm{H}_{2} \mathrm{~S}$ in helium was metered by a Matheson Model 602 rotameter. For the thiophene work, the $\mathrm{H}_{2} \mathrm{~S}$ line was disconnected and plugged, and the thiophene line was added in its place.

Substrate materials used were precleaned glass slides, and GaP substrates. 
Actual flow rates were determined from the rotameter readout with the help of calibration charts from Hamid Kashani's work(29).

To determine actual thiophene flows, vapor pressure data of thiophene was used in combination with Kashani's calibration plots to determine actual concentration of thiophene in the gas stream.

The vapor pressure of thiophene is summarized in Table 2 .

\begin{tabular}{|c|c|}
\hline \multicolumn{2}{|c|}{$\begin{array}{c}\text { Table } 2 \\
\text { Vapor Pressure of Thiophene } \\
\text { as a Function of } \\
\text { Temperature }(22,32)\end{array}$} \\
\hline $\begin{array}{l}\text { Pressure } \\
\text { Temperature } \\
\text { (mag) } \mathrm{Bg})\end{array}$ & $\left({ }^{\circ} \mathrm{C}\right)$ \\
\hline 1 & -40.7 \\
\hline 5 & -20.8 \\
\hline 10 & -10.9 \\
\hline 20 & 0.0 \\
\hline 40 & 12.5 \\
\hline 60 & 20.1 \\
\hline 100 & 30.5 \\
\hline 200 & 46.5 \\
\hline 400 & 64.7 \\
\hline 760 & 84.4 \\
\hline
\end{tabular}


Using the information in Table 2 , with the assumption that the bubbler is at approximately 1 atmosphere pressure and room temperature, the volume concentration of thiophene in helium reaching the reactor should be about $60 / 760 \times 100 \%$ or about $8 \%$ thiophene in helium.

Actual operating procedures for running the MOCVD reactor are included in Appendix $A$. 
IV. Procedures and Results for Thiophene

For the runs using thiophene, the $\mathrm{H}_{2} \mathrm{~S}$ line was

disconnected upstream from the rotameter and plugged. A thiophene assembly was installed consisting of a plumbing

line from a tank of pure He leading directly to the reactor. Branching off this line was a link which flowed through the thiophene bubbler, and then met right back up with the pure He line. A schematic of the thiophene assembly is shown below.

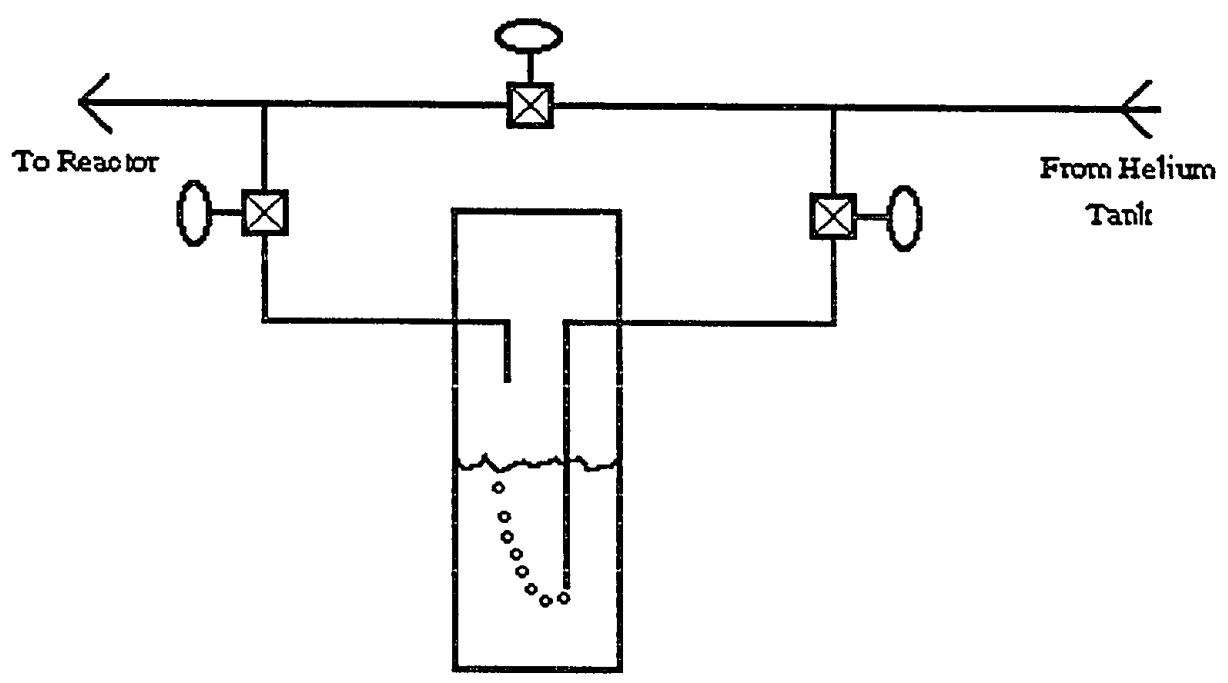

Figure 11. Schematic of thiophene line. Thiophene line used in the growth of zns by MOCVD. Note the three manually operated valves with which the direction of gas flow can be directed through the bubbler, or can bypass the bubbler and flow directly on to the reactor. 
The thiophene line then continues on to the reactor.

Growths were carried out under the following range of conditions, also shown in Table 3 :

$$
\begin{array}{ll}
\text { [thiophene + He] flow rate } & 26-56 \mathrm{sccm} \\
\text { growth temperature } & 300-500^{\circ} \mathrm{C} \\
\text { chamber pressure } & 1-10 \text { torr }
\end{array}
$$

During some of these runs, especially at the higher growth temperatures, there was some carbonaceous material on the susceptor after deposition. There were, however, no Zns deposits in any of the runs using the thiophene source.

The growth temperature limitation is one possible reason why Zns deposition did not occur. Previous investigations $(15,16)$ showed that the use of other sources, like DES and $\mathrm{CS}_{2}$, required higher growth temperatures for deposition to occur. In the case of DES, the minimum growth temperature necessary, without photo-assist was $400^{\circ}$ C, as shown in Figure 8. However, growth temperatures in the current work were taken as high as $500^{\circ} \mathrm{C}$, still resulting in no deposit. It seems that some growth would have occurred if temperature were the dominating factor. The pressure limitation is another possibility inhibiting the successful use of thiophene. The growth of ZnS by other researchers using sources other than $\mathrm{H}_{2} \mathrm{~S}$ has all been carried out at higher pressures. $\mathrm{CS}_{2}$ was used at pressures ranging from 160-360 torr, and DES was used at a 
pressure of 760 torr. The MOCVD reactor used for this work was designed for use at pressures in the range of 1-10 torr. It is possible that operating pressures are not high enough for the use of thiophene.

The work of Jones, et al.(14) further reinforces the possibility that higher pressures are necessary for the use of thiophene. Their work was carried out at 760 torr.

In summary, a series of runs was carried out with thiophene, and although no growths resulted from that work, a likely reason for this is that higher operating pressures are needed for thiophene. 


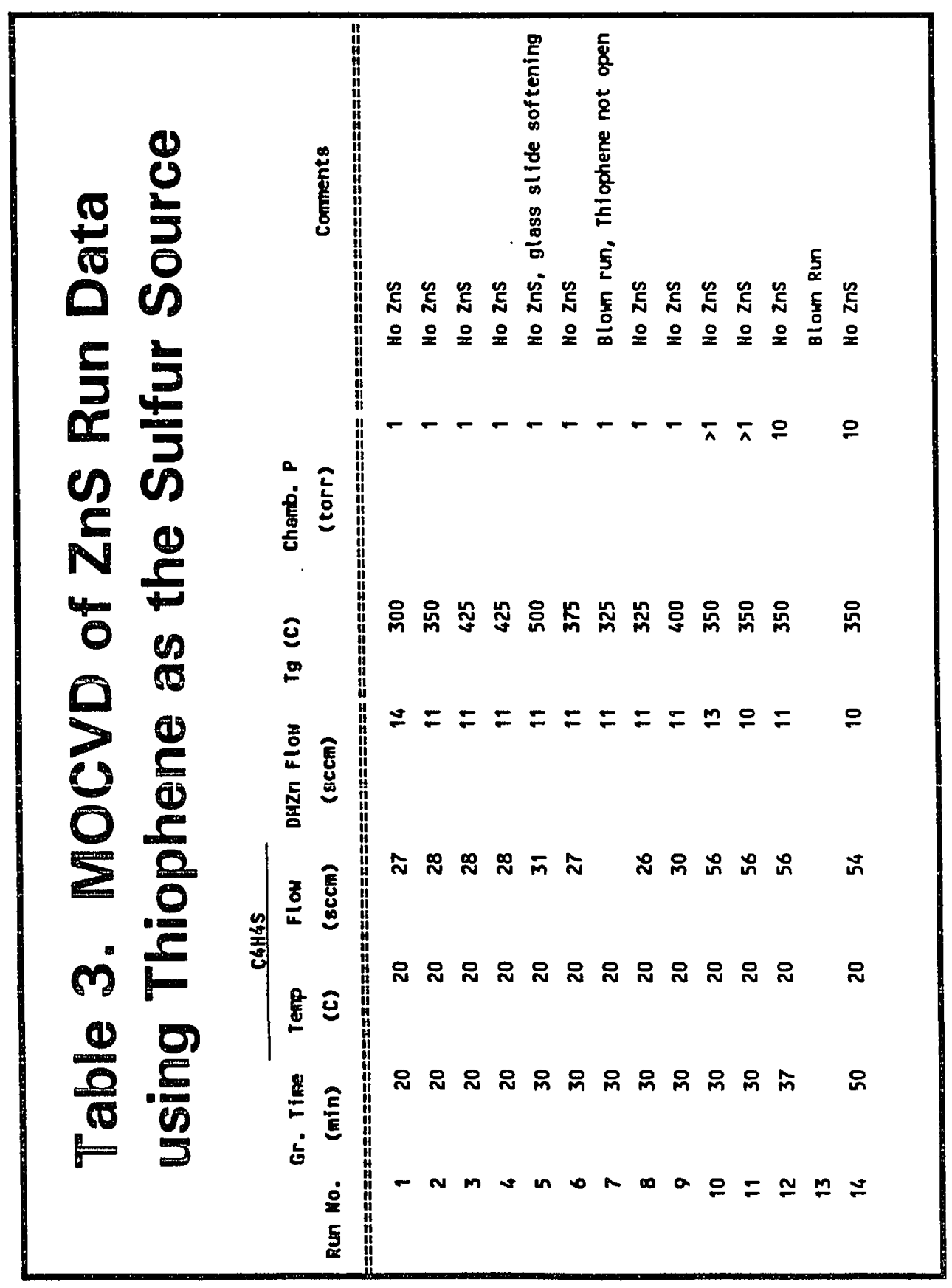

m 


\section{v. Procedures and Results for $\mathrm{H}_{2} \mathrm{~S}$}

After failing to get $\mathrm{zns}$ deposition using thiophene, the thiophene line was disconnected, and the $\mathrm{H}_{2} \mathrm{~S}$ line reattached. It was desired to obtain an idea of growth rate trends as a function of flow rate of $\mathrm{H}_{2} \mathrm{~S}$ and DMZn, and as a function of growth temperature. For evaluation of the runs using $\mathrm{H}_{2} \mathrm{~S}$, a $2^{3}$ factorial design was used, resulting in eight runs for study of $\mathrm{H}_{2} \mathrm{~S}$ growth trends.

The data from these runs with the hydrogen sulfide reconnected is shown in Table 4.

For all the runs using $\mathrm{H}_{2} \mathrm{~S}$, a cover slip was mounted on the substrate, positioned so that its edge would coincide with the estimated center of deposition. After growth, the cover slip was discarded and thickness measurements on the substrate were made using a Tencor Model 250 Thickness Profiler located at Hewlett-Packard. Several measurements were made searching for the point where thickness was greatest, indicating the center of deposition. 


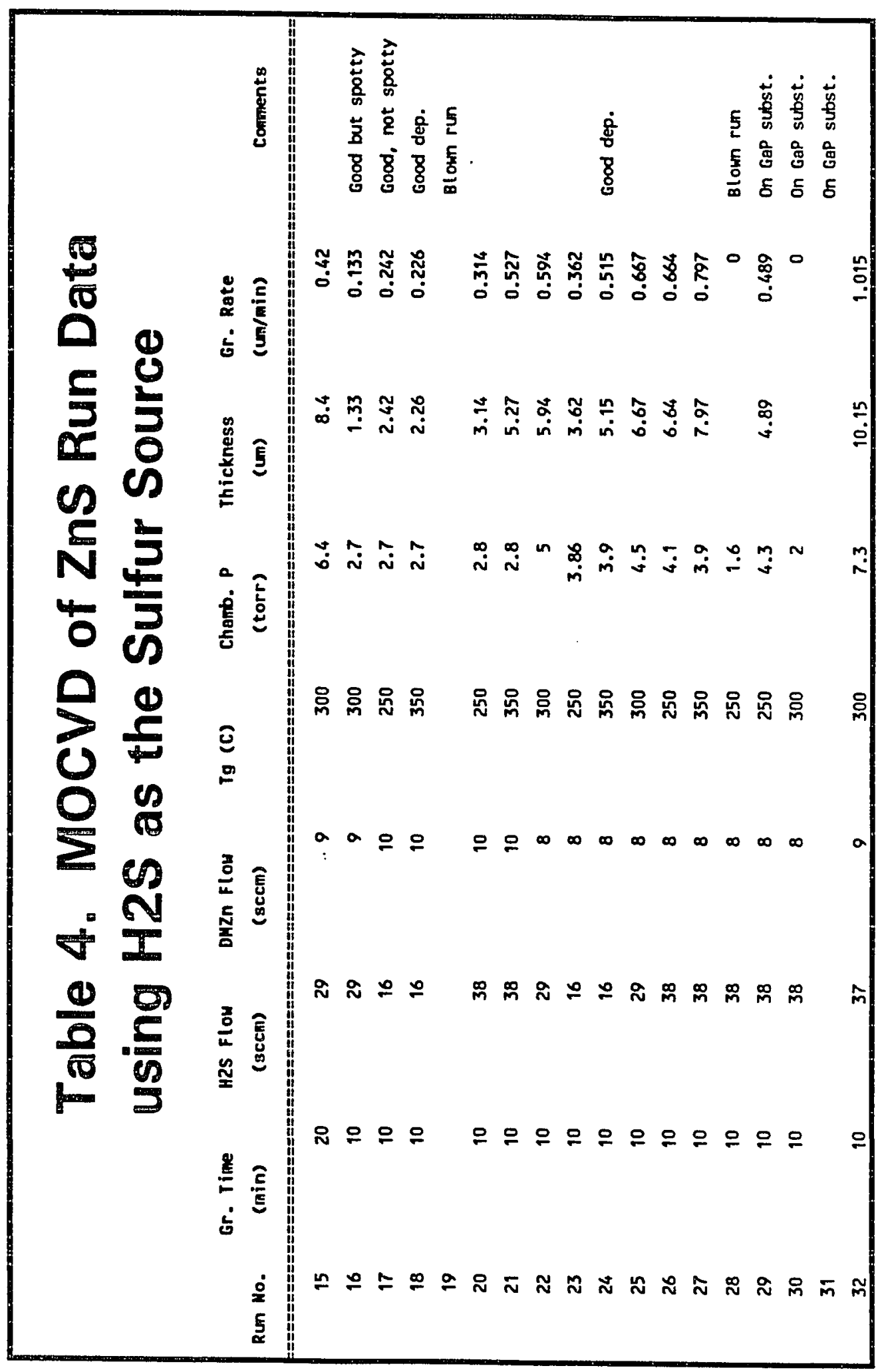


Surface morphology was evaluated using an olympus microscope equipped with Differential Interference Contrast (DIC) capability. The surface morphology was uniform in appearance, with a grainy texture and very little spottiness. Typical surface morphology on these wafers is shown in Figure 12. These micrographs were taken at $50 \mathrm{x}$ and $500 x$.

A cross-sectional photograph taken at 1500x magnification on a cleaved piece of run \#29 on GaP substrate shows the polycrystalline nature of the layer in Figure 13. Finally, in Figure 14, a photo of an EDX spectrum confirms the presence of zinc sulfide.

Reproducibility of $\mathrm{znS}$ layers grown was also addressed. Run numbers 16,22 , and 25 were all grown at the same nominal temperature and flow rates. However, the pressure varied significantly in these three runs due to the difficulty of controlling pressure with a manually operated pressure control valve, and cannot be considered as a valid measure of reproducibility of thin films grown in this reactor.

The data points from Table 4 were manipulated into a series of graphs, each graph factoring out all but two variables. This series of graphs is shown in Figures 1526. For instance, in Figure 15, of the three parameters 
studied affecting growth rate, $\mathrm{H}_{2} \mathrm{~S}$ flow, DMZn flow, and growth temperature, data points were chosen with the growth temperature fixed at $250^{\circ} \mathrm{C}$. There are two data lines in Figure 15. One corresponds to DMZn flow fixed at $8 \mathrm{sccm}$, and the other corresponds to DMZn flow at $10 \mathrm{sccm}$. Once these variables are factored out, the remaining two variables, $\mathrm{H}_{2} \mathrm{~S}$ flow and thin film thickness were plotted against one another. So in summary, Figures 15 through 18 examine film thickness versus sulfur flow with different combinations of the other two variables held constant, Figures 19-22 show film thickness versus DMZn flow, and Figures 23-26 show film thickness versus growth temperature. All of these growths were 10 minutes in duration, so the extensive variable growth time was plotted in place of the intensive variable growth rate in all of these graphs.

The graphs shown in Figures 15-26 suggest trends in what influences the growth rate. For example in Figures 15-18, every data line shows an increase in growth rate when the $\mathrm{H}_{2} \mathrm{~S}$ is increased.

The next four figures, Figures 19-22, show a decrease in growth rate with an increase in DMZn, which is a little harder to explain. A key for the reason to this may be found in the work by Yoshikawa(8). In his work, when he was evaluating the effect of [DMZn + He] flow on growth 
rate of $\mathrm{ZnS}$, he was able to compensate for an increase in the [DMZn + He] flow by reducing the flow of the ballast He by an equal amount. He was, in this way, able to increase the amount of zinc precursor delivered to the reactor, but at the same time keep constant the sum of all flows into the reactor to achieve a true evaluation of the dependence of flow of DMZn on the growth rate.

In the case of San Jose State's MOCVD reactor, such an evaluation was not possible. In Figures 19-22 which show the effect of growth rate on DMZn flow, the total flow into the reactor is increasing when the [DMZn $+\mathrm{He}]$ flow is increased. This leads to the possibility that there is actually a geometric effect reducing the growth rate with increasing [DMZn + He] flow. Since the DMZn that enters the reactor enters just above and flowing directly toward the substrate, it is likely that increasing its flow is inhibiting the flow of $\mathrm{H}_{2} \mathrm{~S}$ to the substrate. This would naturally cause a reduction of the growth rate as the amount of a stoichiometric mix of $z$ inc and sulfur has been reduced by raising the [DMZn + He] flow.

Figures 23-26 show film thickness as a function of growth temperature. Once again, these four figures show a direct relationship between film thickness and growth temperature. However, if this evaluation was carried out over a broader range, there should be a temperature where 
growth rate will be maximized, and above this temperature an inverse relationship will be exhibited. This is due to the increasing effect of desorption of reactants from the substrate as temperature is increased. 

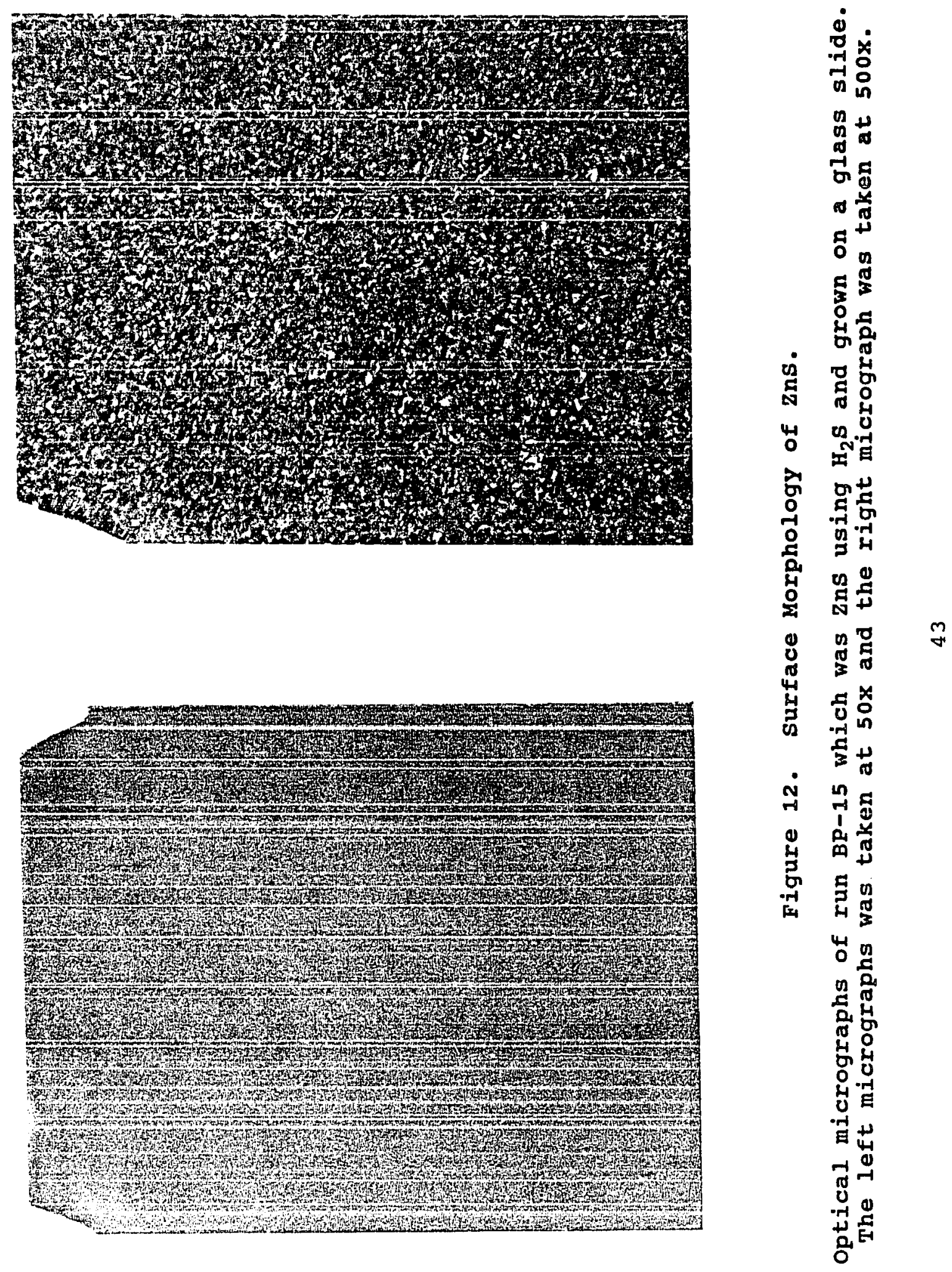

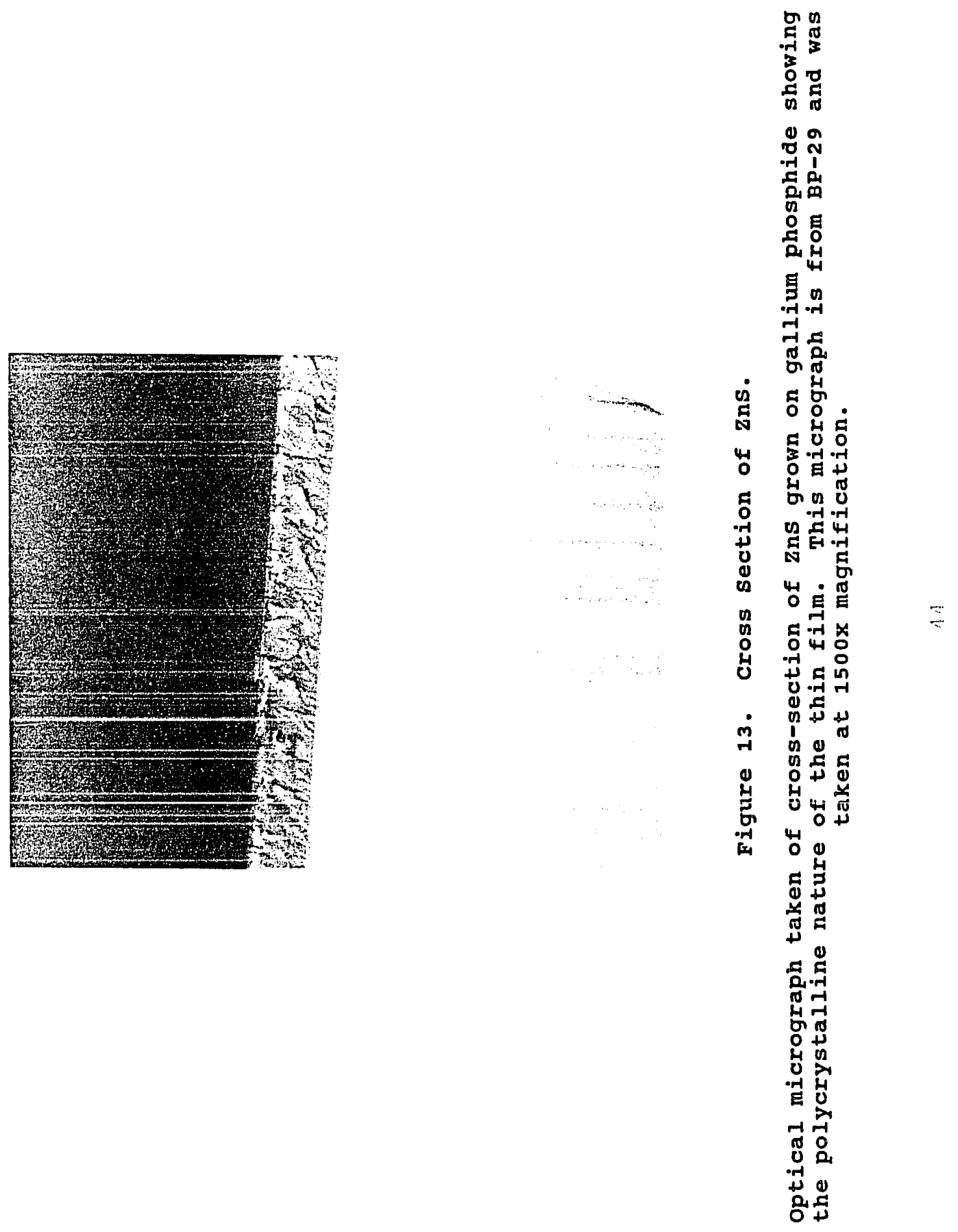


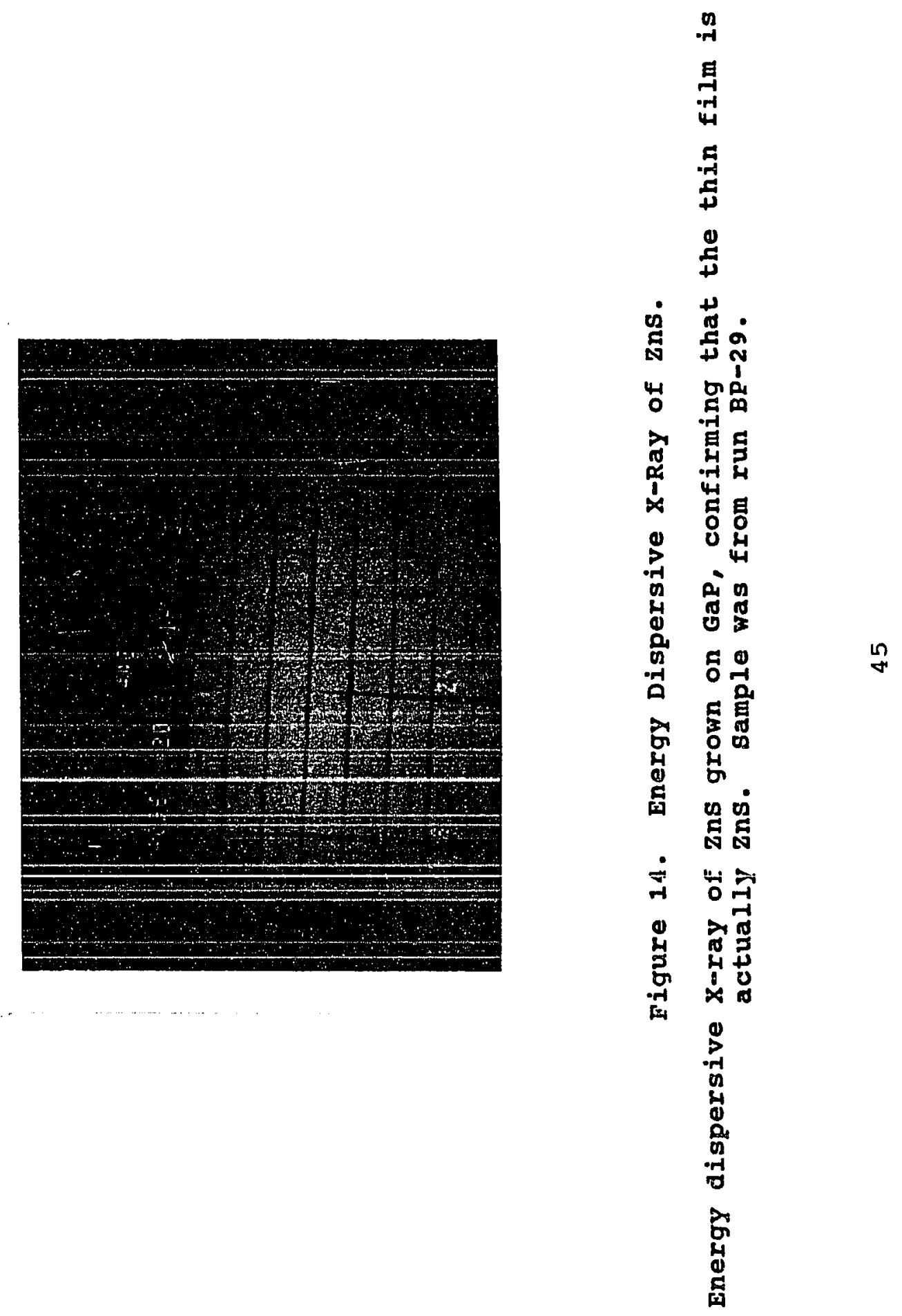




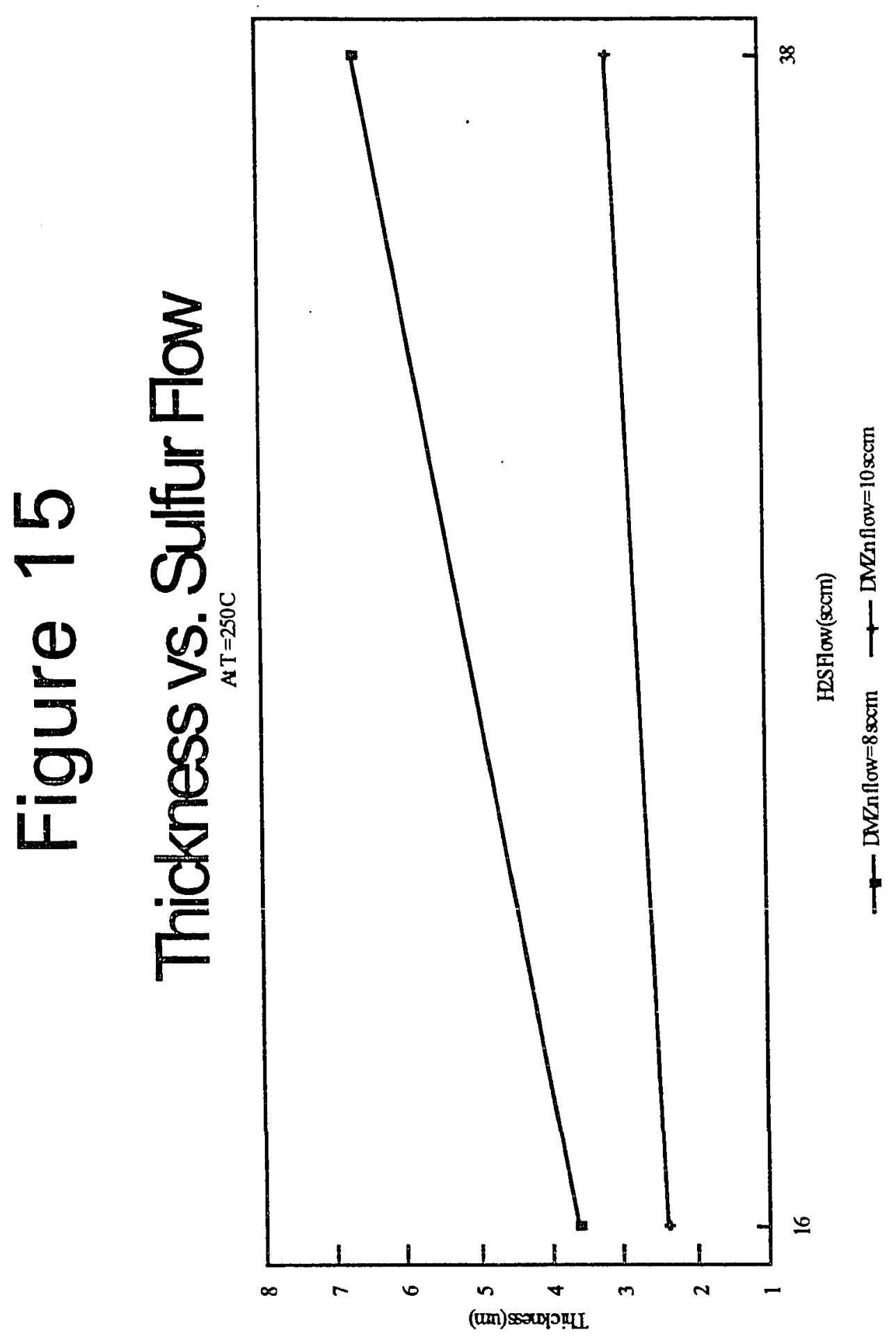




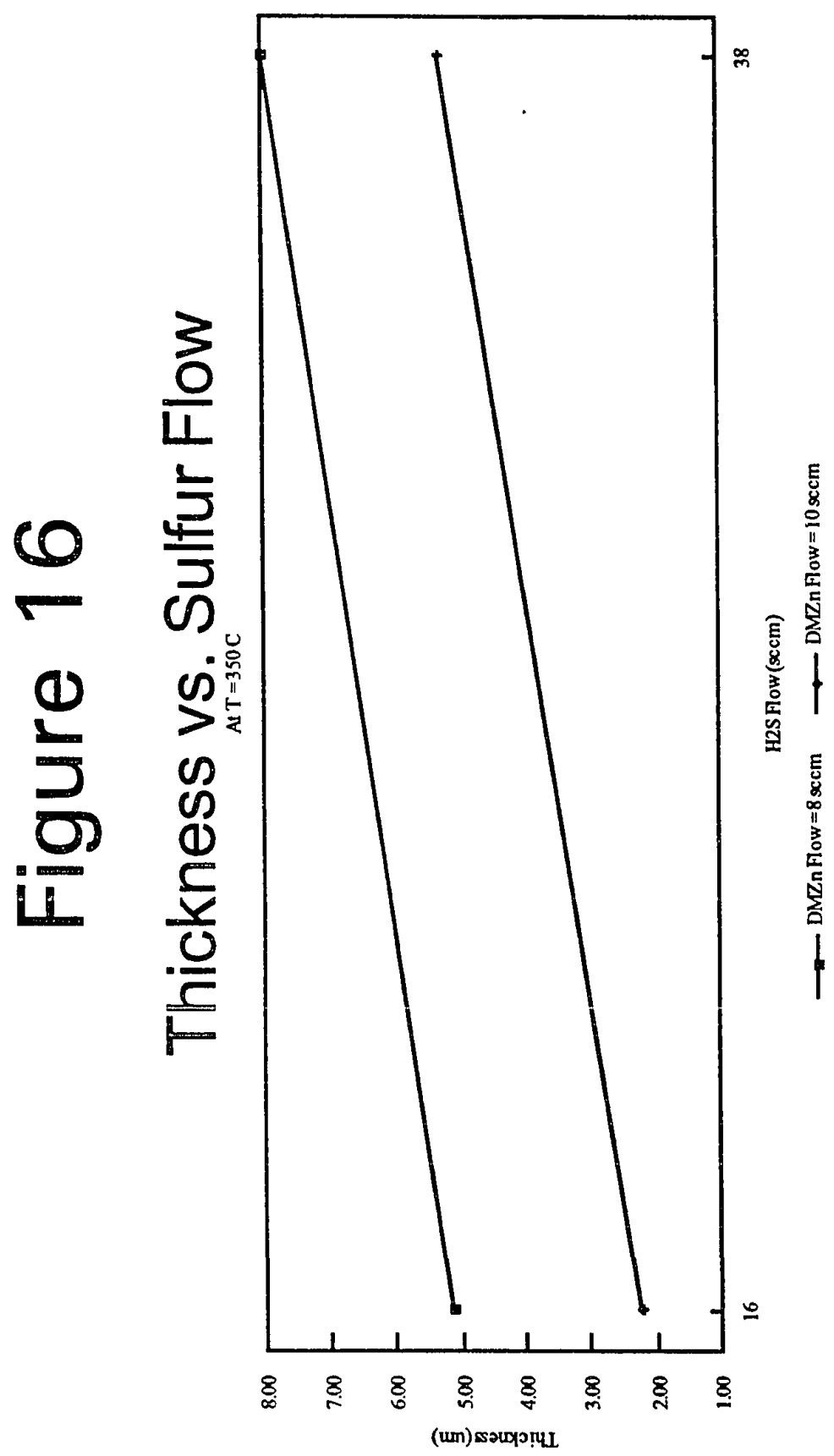

5 


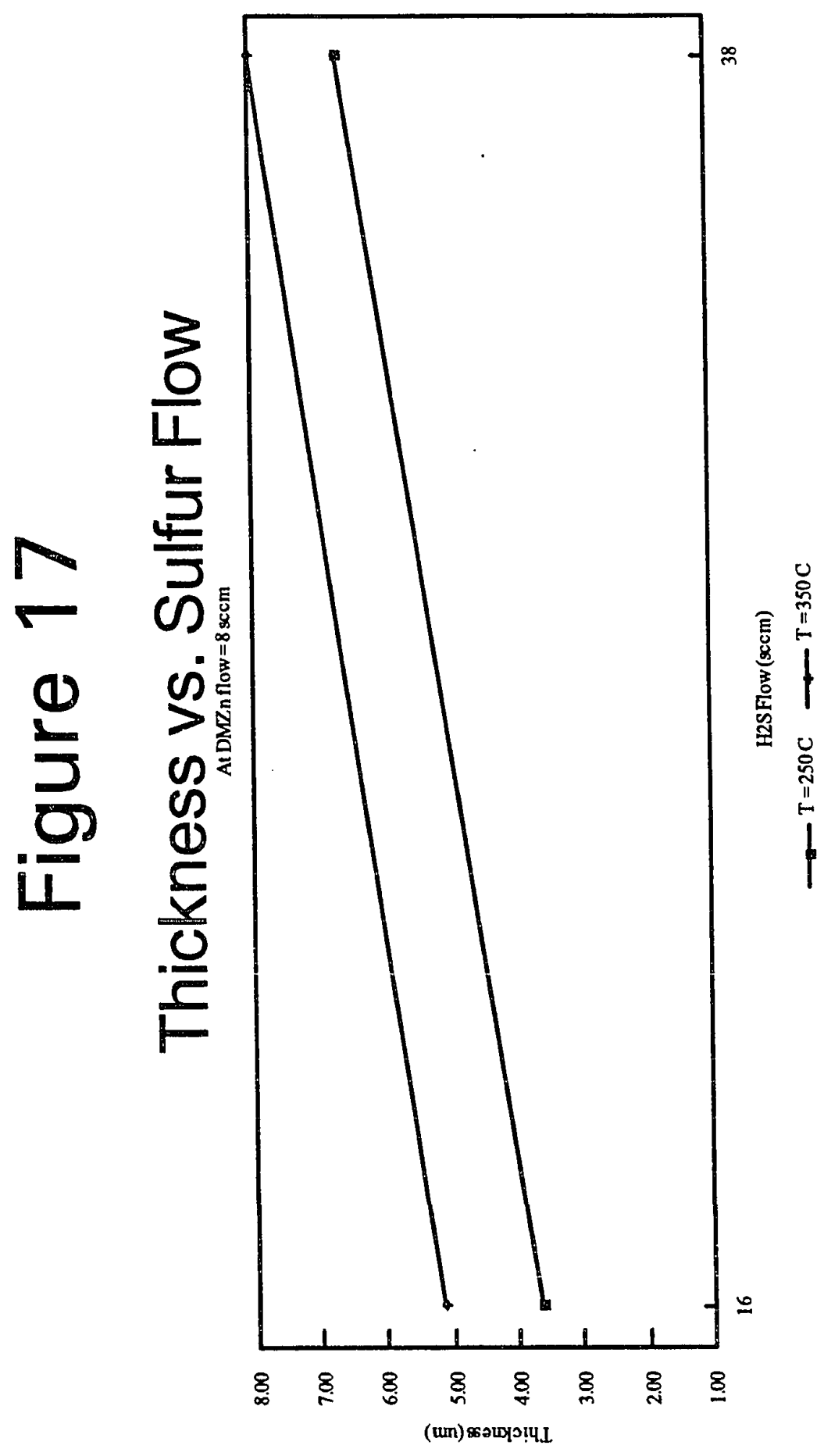

$\stackrel{\infty}{\forall}$ 


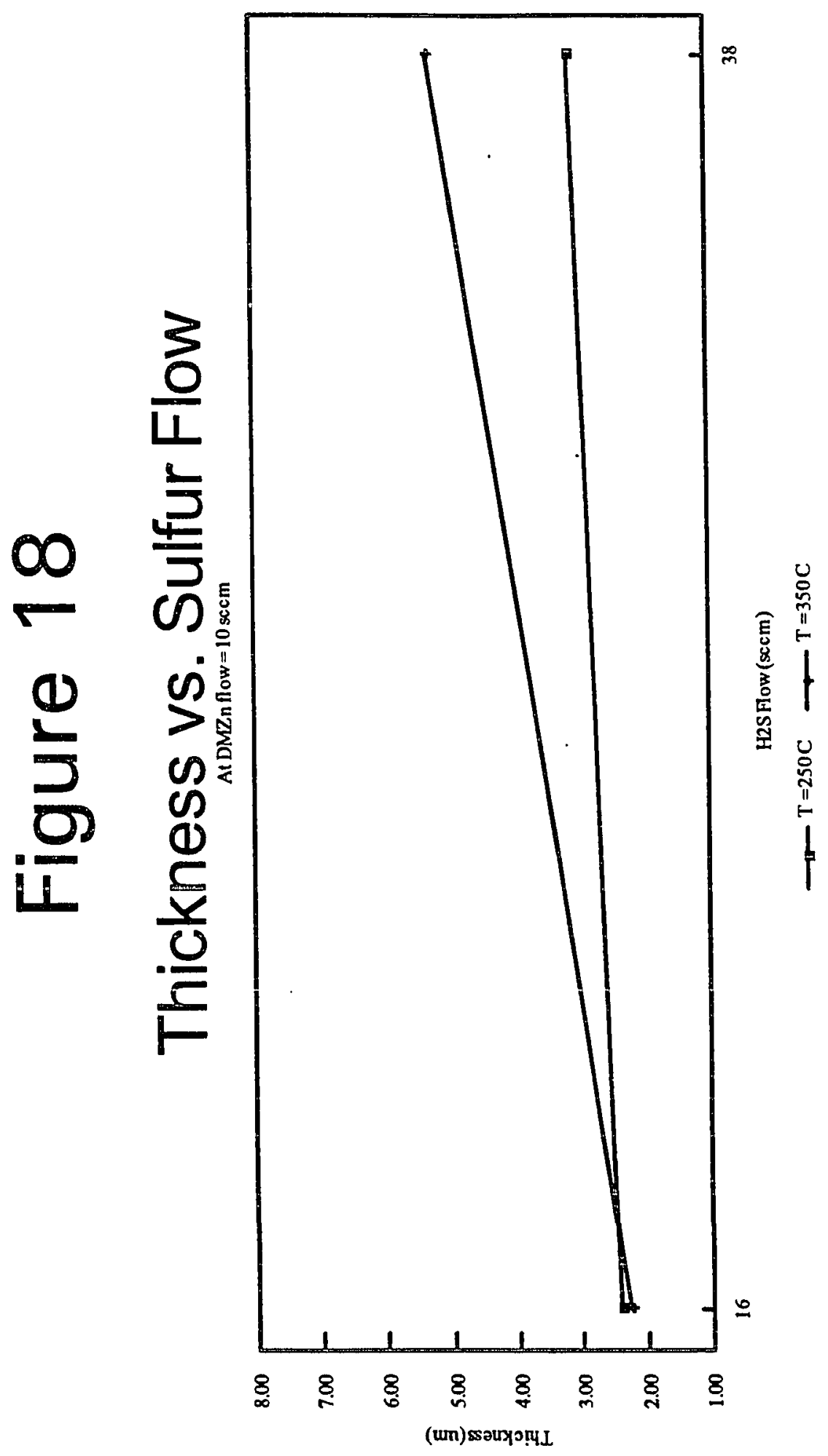

$g$ 




오 


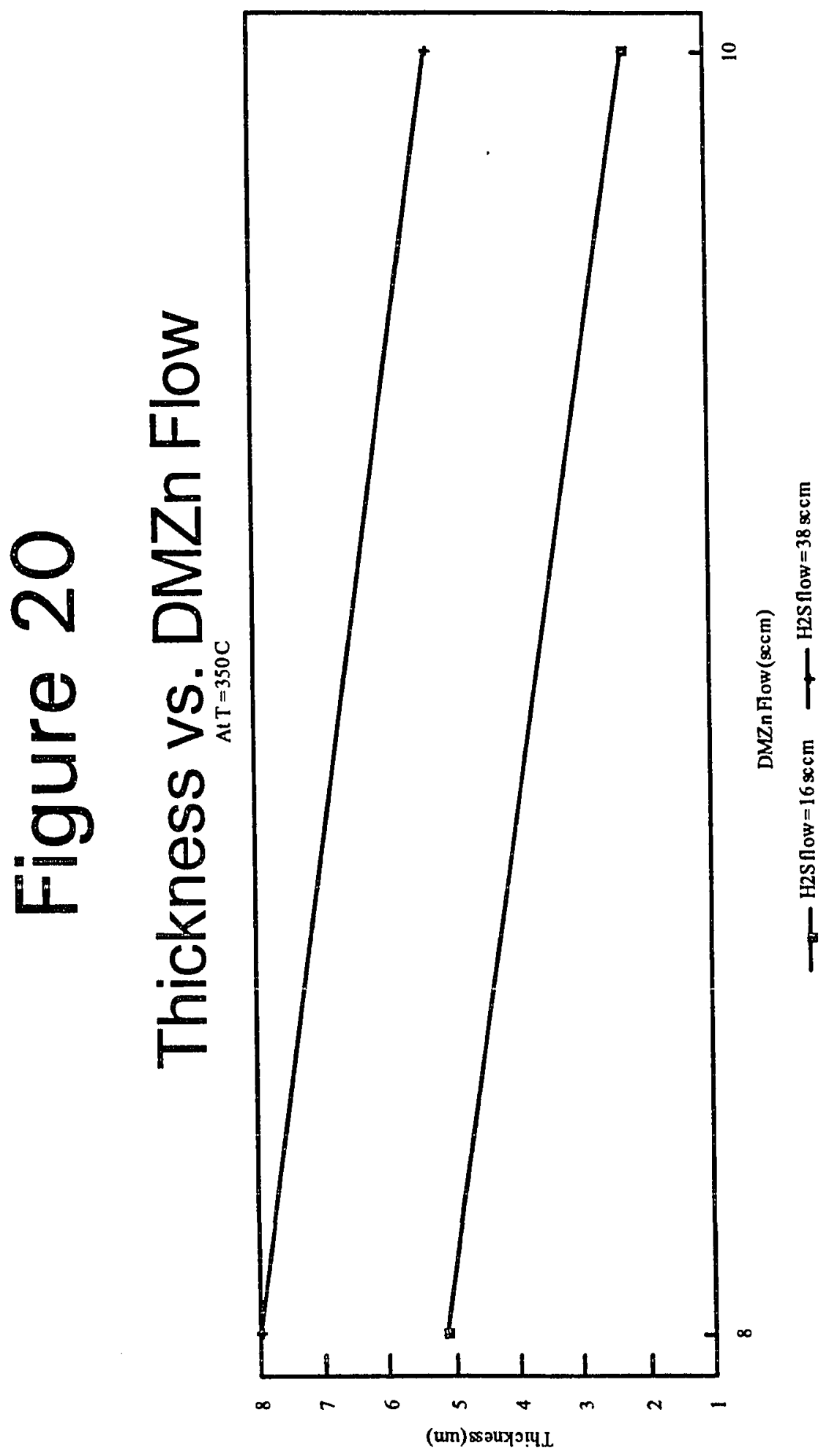




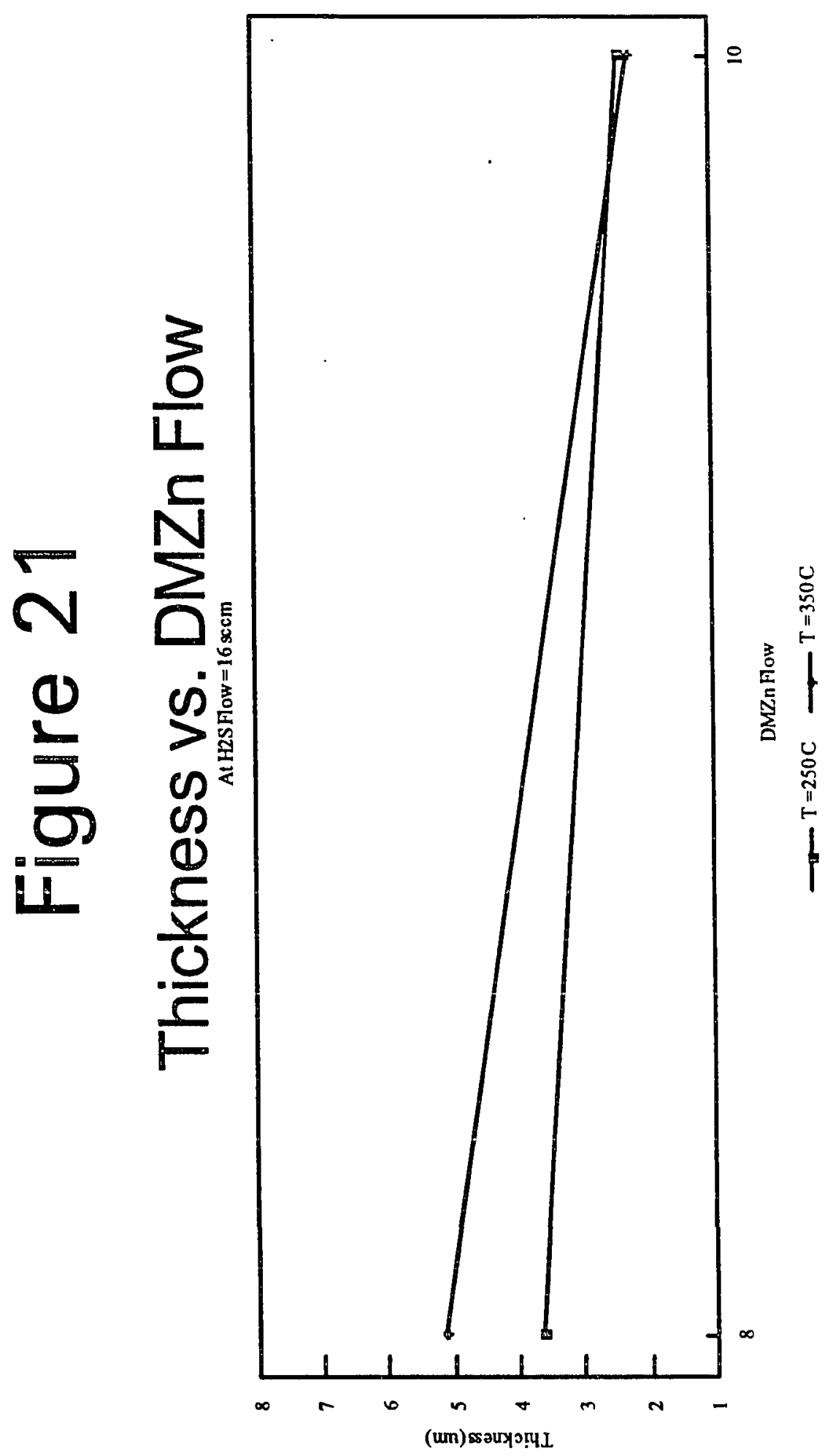




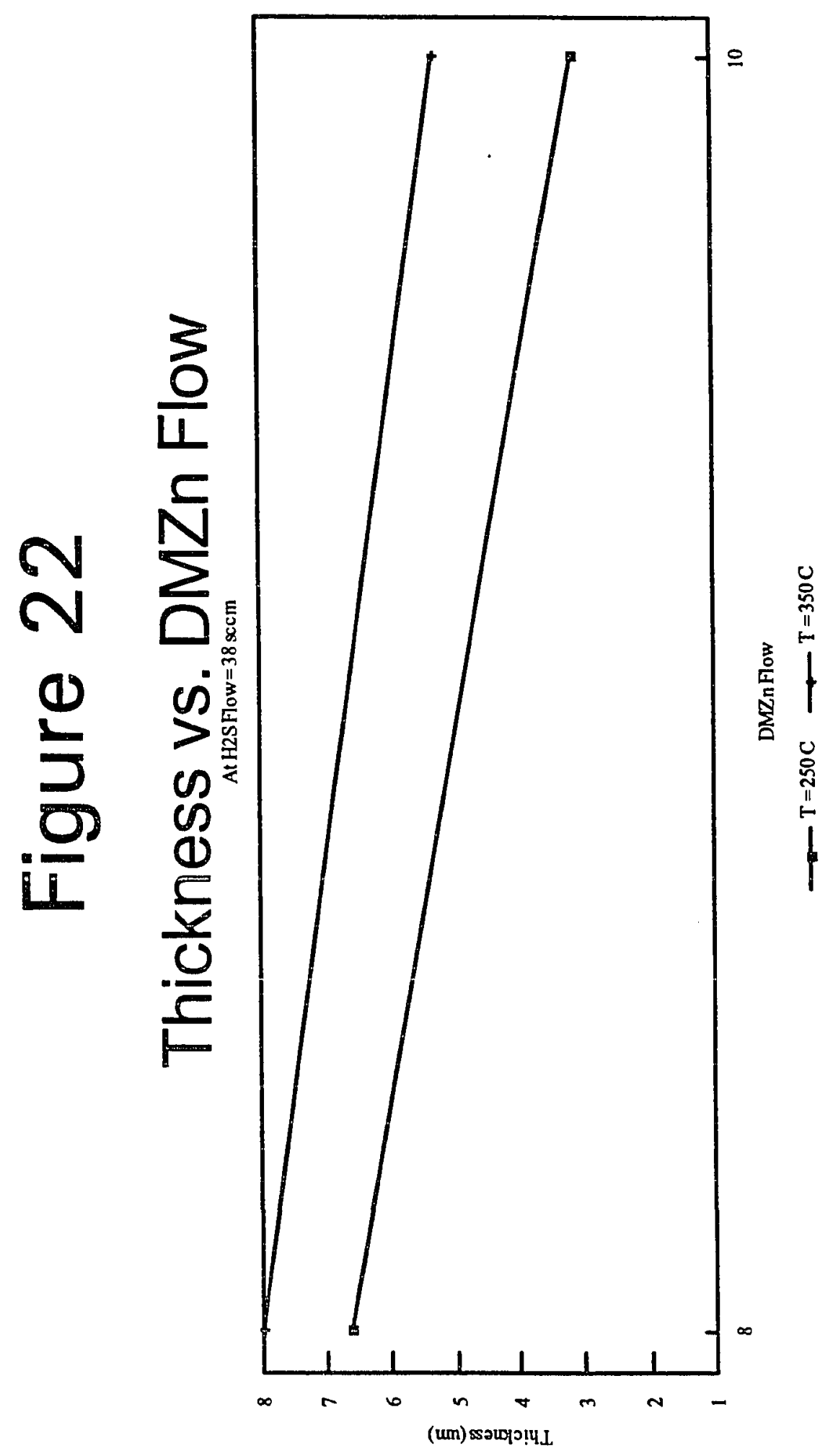

กี 


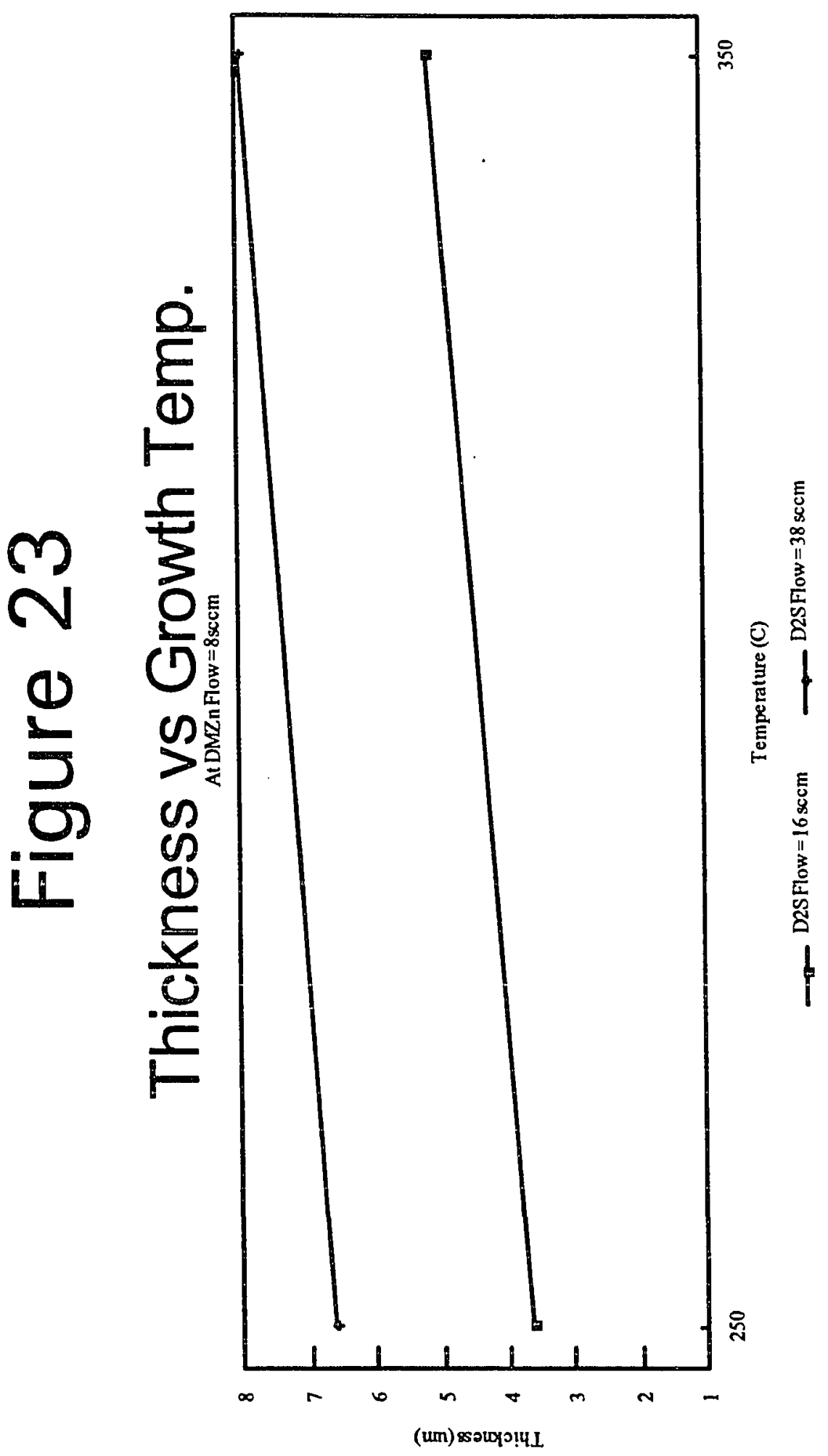

เั 


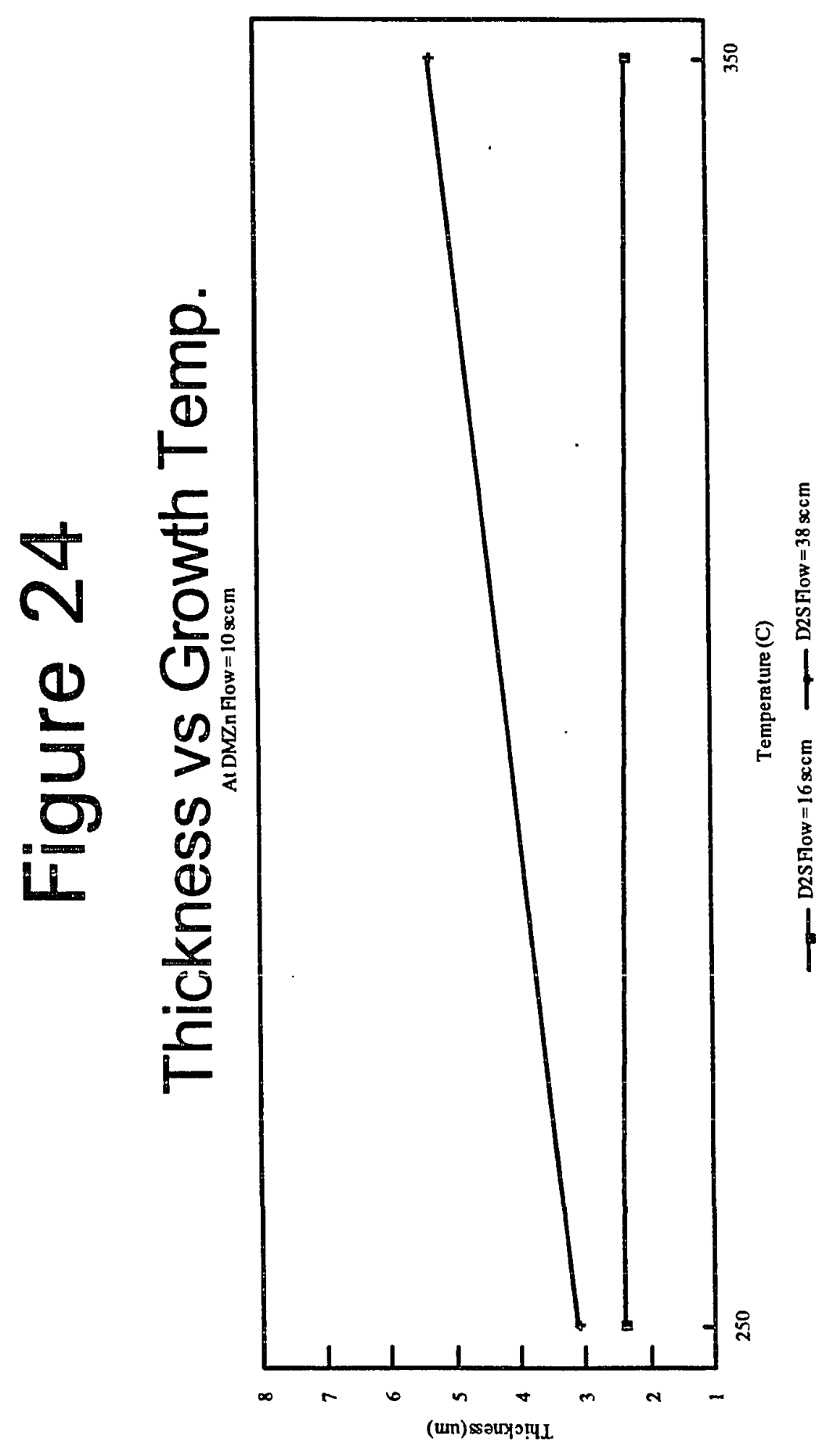




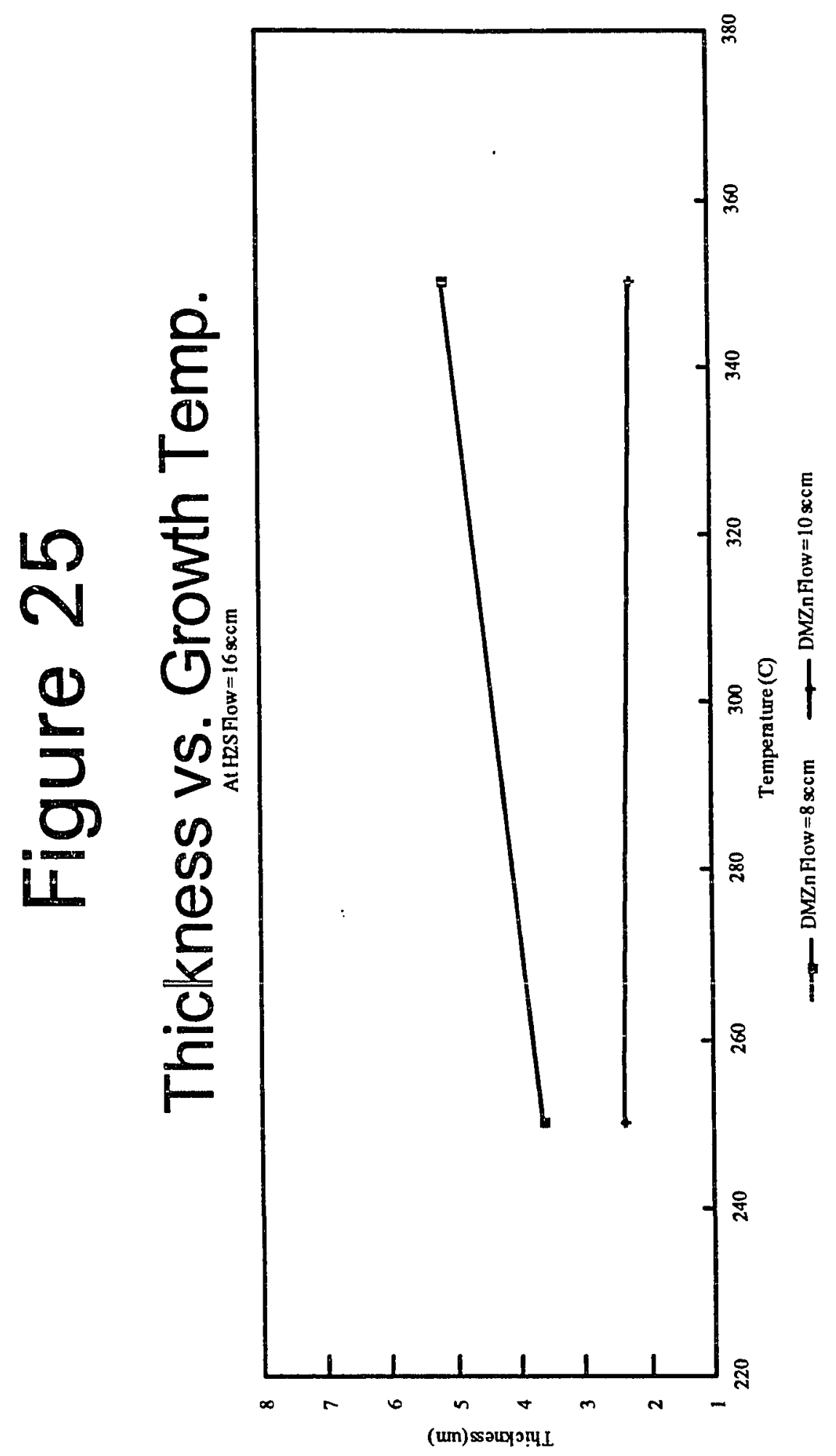

in 


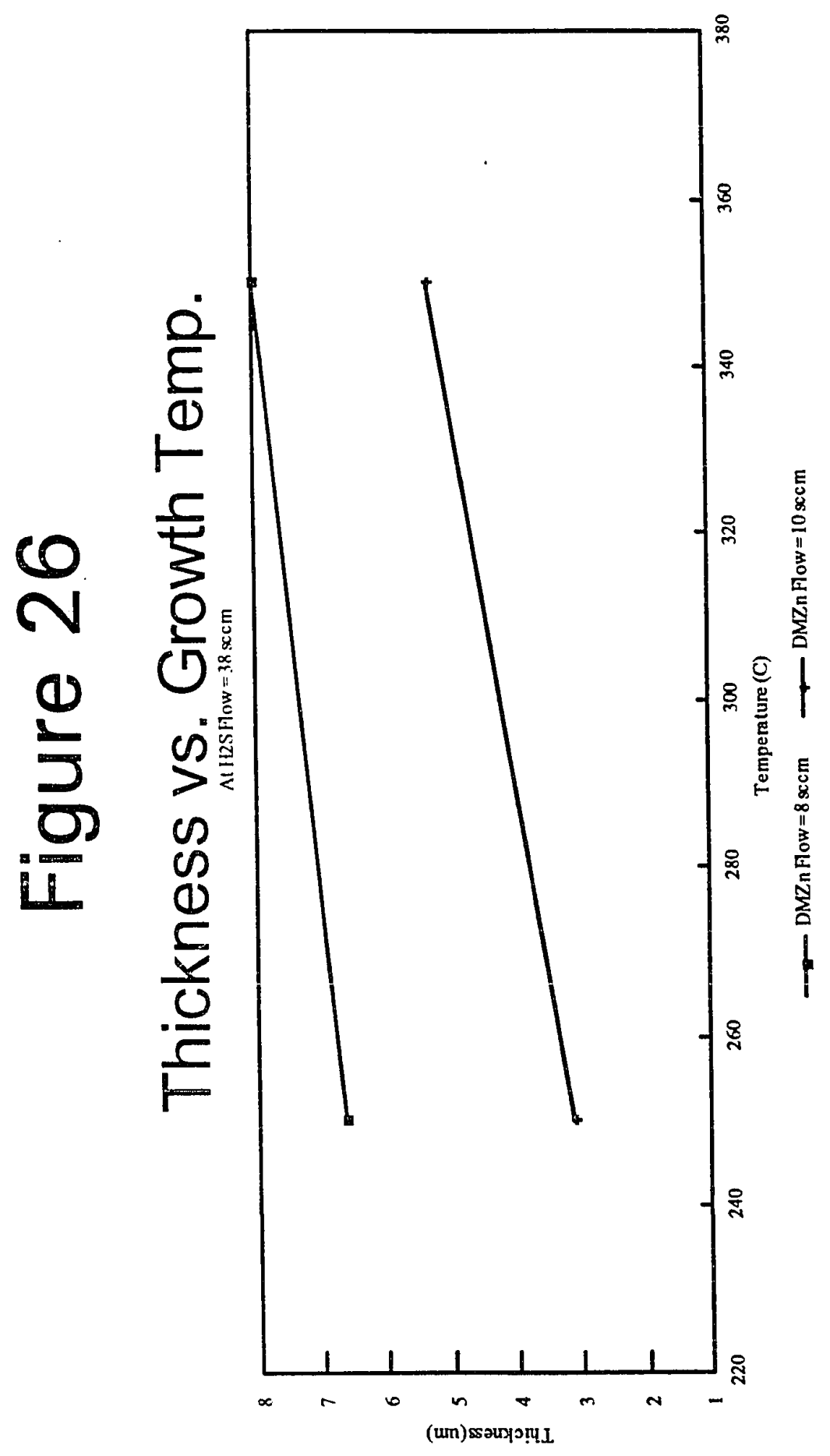

กิ 


\section{Conclusion}

Use of thiophene in this reactor is not feasible at present. A recommendation would be to try a different liquid sulfur source such as carbon disulfide for which lower growth temperatures have been reported than for thiophene and DES. But first it would be better to modify the reactor to operate at higher pressures. The present 1015 torr maximum just isn't high enough for any sulfur source but $\mathrm{H}_{2} \mathrm{~S}$.

Very good growth rates are obtainable with the use of $\mathrm{H}_{2} \mathrm{~S}$, and the reactor is well suited for use in the optimum range of this source.

The data obtained from using the $\mathrm{H}_{2} \mathrm{~S}$ showed that the growth rate was directly related to the $\left[\mathrm{H}_{2} \mathrm{~S}+\mathrm{He}\right]$ flow and to growth temperature. However, there was an apparent inverse relationship between [DMZn + He] flow and growth rate. This was due to the fact that increasing the DMZn flow unavoidably increased the flow of its carrier gas and inhibited the ability of $\mathrm{H}_{2} \mathrm{~S}$ to reach the substrate and react with the DMZn.

Surface morphology of the runs using $\mathrm{H}_{2} \mathrm{~S}$ overall had a uniform grainy appearance and thickness of the layers had a more or less radial distribution. 


\section{References}

1. P.A. Tipler, Physics, worth Publishers, New York, 1976, p. 962 .

2. F.W. Sears, M.W. Zemansky, and H.D. Young, University Physics, Addison-Wesley Publishing Company, Menlo Park, California, 1977, p. 792 .

3. D. Seto, C. Rohrabacher, J. Seto, and L. Hood, Phosphorescent $z$ inc Sulfide Is a Nonradiative Alternative for Marking Autoradiograms, Analytical Biochemistry, Vol. 189, No. 1, 1990, p. 51.

4. B. Greenberg, W.K. Zwicker, and I. Cadoff, ZnS Epitaxy on Sapphire, Thin Solid Films, Vol. 141, 1986, p. 89.

5. T. Suntola, Atomic Layer Epitaxy, Thin Solid Films, Vol. 216, 1992, p. 84 .

6. A. Yoshikawa, H. Oniyama, S. Yamaga and H. Kasai, A study of Growth Mechanisms of $\mathrm{ZnS}$ and $\mathrm{ZnSe}$ in MOMBE Using Dimethylzinc and Chalcogen Hydrides as Reactants, Journal of Crystal Growth, Vol. 95, 1989, p. 572.

7. J.I. Vossen, and W. Kern, Eds., Thin Film Processes II, Academic Press, Inc., San Diego, California, 1991, p. 135 .

8. A. Yoshikawa, A. Sirai, S. Yamaga, and H. Kasai. Growth Mechanism of $\mathrm{ZnS}$ and ZnSe Films in Low-Pressure MOCVD, Japanese Journal of Applied Physics, Vol. 25, No. 5, May 1986, pp. 673-678.

9. P.J. Wright, and B. Cockayne. The Organometallic Chemical Vapour Deposition of $\mathrm{ZnS}$ and $\mathrm{ZnSe}$ at Atmospheric Pressure, Journal of Crystal Growth, Vol. 59 , 1982, pp. 148-154.

10. J.L. Vossen, and W. Kern, Eds. Thin Film Processes, Academic Press, Inc., Orlando, Florida, 1978, p. 284.

11. K. Hirabayashi, and 0. Kogure, Epitaxial Growth of $\mathrm{znS}$ on Si by Metal organic Chemical Vapor Deposition, Japanese Journal of Applied Physics, Vol. 24, No. 12, Dec. 1985, p. 1590. 
12. S. Fujita, Y. Tomomura, and A. Sasaki, Growth of $z$ ns by Metalorganic Chemical Vapor Deposition, Japanese Journal of Applied Physics, Vol. 22, No. 9, Sep. 1983, p. L583.

13. A. Yoshikawa, S. Yamaga, and K. Tanaka, New and Siimple MOCVD Technique Using Completely Gaseous Mo-Sources Especially Useful for Growing $2 n$-Chalcogenide Films, Japanese Journal of Applied Physics, Vol. 23, No. 6, June 1984, pp. L388-L390.

14. A.C. Jones, P.J. Wright, and B. Cockayne, Precursors for II-VI Semiconductors: Requirements and Developments, Journal of Crystal Growth, Vol. 107, 1991, pp. 297-308.

15. S. Takata, T. Minami, T. Miyata, and H. Nanto, High Quality zinc Sulfide Thin Films Grown by MOCVD Using Carbon Disulfide as a Sulfur Source, Japanese Journal of Applied Physics, Vol. 27, No. 2, Feb. 1988, p. L247.

16. K. Hirabayashi and H. Kozawaguchi, Photo-Assisted Metal Organic Chemical Vapor Deposition Preparation of Polycrystalline ZnS:Mn Films for Thin Film Electroluminescent Devices, Japanese Journal of Applied Physics, Vol. 28, No. 5, May 1989, p. 814.

17. Material Safety Data Sheet for Dimethylzinc Organometallic Gas Mixtures, Airco, Division of The BOC Group, Inc., Murray Hill, New Jersey.

18. N.I. Sax, Dangerous Properties of Industrial Materials, Von Nostrand Reinhold Company, New York, 1979, p. 731.

19. Op. cit., p. 469 .

20. Op. cit., p. 674 .

21. Material Safety Data Sheet for Diethylzinc organometallic Liquid, Alfa Products, Division of Morton Thiokol, Inc., Danvers, Massachusetts.

22. R. Weast, Ed., CRC Handbook of Chemistry and Physics, 61st Ed., CRC Press, Inc., Boca Raton, Florida, 1980.

23. K. Hirabayashi and 0 . Kogure, AC-Thin Film znS:Mn Electroluminescent Device Prepared by Metal Organic Chemical Vapor Deposition, Japanese Journal of Applied Physics, Vol. 24, No. 11, Nov. 1985, p. 1484. 
24. T. Minami, T. Miyata, K. Kitamura, H. Nanto, and S. Takata, Low Voltage Driven MoCVD-Grown ZnS:Mn Thin Film Electroluminescent Devices Using Insulating $\mathrm{BaTiO}_{3}$ Sheets, Japanese Journal of Applied Physics, Vol. 27, No. 5, May 1988 , p. L876.

25. M. Migita, O. Kanehisa, M. Shiiki, and H. Yamamato, The Preparation of ZnS:Mn Electroluminescent Layers by MOCVD Using New Manganese Sources, Journal of Crystal Growth, Vol. 93, 1988, p. 686 .

26. M. Jensen, Materials Engineering Senior Project, San Jose State University, 1986.

27. H. Do, Materials Enginering Senior Project, San Jose State University, 1988.

28. D. Ramos, Materials Engineering Master's Thesis, San Jose State University, December 1988.

29. H. Kashani, Metal-Organic Chemical Vapor Deposition (MOCVD) of Zinc Sulfide Film by Utilizing Dimethylzinc and Hydrogen Sulfide Gases, Materials Engineering Master's Thesis, San Jose State University, October 1988 .

30. D.-z. Chuang, Fabrication and Performance of AC ThinFilm Electroluminescent Devices Using MOCVD Prepared ZnS:Mn Phosphor Layers, Materials Engineering Master's Thesis, San Jose State University, May 1992.

31. R. Patten, Materials Engineering Senior Project, San Jose State Universtiy, 1991.

32. Material Safety Data Sheet for Thiophene Orgnosulfur liquid, Alfa Products, Thiokol/Ventron Division, Danvers, Massachusetts. 


\section{Appendix \\ HoCVD Operating Procedures}




\section{MOCVD OPERATING PROCEDURES}

I. Turning the $\mathrm{H}_{2} \mathrm{~S}$ toxic detector on.

-- Pull pin out of the top of the meter (unit will start beeping).

-- Hit alarm button (beeping should go off).

II. Turning on the power to the control panel.

-- Flip up main breaker, turn on "power" on the left side of the control panel.

-- Turn on burner switch on control panel (to the right of the power switch). Let warm up about one minute.

-- Open yellow valve on wall behind the gas box which is at about eye height. This turns on the scrubber water.

-- Open air to burner valve (red tube hanging down above MOCVD control panel) slightly. Check for flow by disconnecting at union above the gas cabinet. There should be a low flow. Reconnect union.

-- Flip on burner VARIAC power switch and set output initially at 10. Increment output slowly up to 110 during the start-up process.

-- Check for draw in gas cabinet (use a piece of paper to test flow). 
-- Use toxic detector to check for $\mathrm{H}_{2} \mathrm{~S}$ presence in gas cabinet.

-- Increment burner output a little more. Ultimately, you want $1000^{\circ} \mathrm{C}$ corresponding to a VARIAC output of about 110.

III. Bringing chamber up to atmosphere for substrate loading/unloading:

-- Open $\mathrm{N}_{2}$ cylinder valve (don't change regulator pressure--make sure it's left at $15 \mathrm{psi}$ ).

-- Press V3 $\left(\mathrm{N}_{2}\right.$ valve) on front panel. This starts $\mathrm{N}_{2}$ flow into the reactor.

-- Watch vacuum gauge on top of reactor chamber. When at 1 atm, pull out susceptor.

-- Disconnect thermocouples at susceptor holder.

-- Unplug heater power cord.

-- Bring out susceptor.

-- Load substrate.

-- Turn on mechanical pump (front panel).

-- Flip vac-to-air valve off (down position).

-- Insert susceptor back into the chamber and close.

-- Open hand vac valve to draw vacuum.

-- Turn off Valve 3 on Control panel.

-- Reconnect thermocouple. On chamber door, the upper TC port measures at the susceptor, and the lower TC port measures below the susceptor. 
Note: On back of MOCVD control panel, only the top thermocouple wire works, so use only that one and plug into the desired TC port on the reactor chamber door.

-- Reconnect heater power cord.

IV. Evacuating chamber and stabilizing at low pressure.

-- Open the hand vacuum valve to begin pump down.

-- When the pressure reaches about 40 microns, turn on $\mathrm{V} 3$ valve to alow $\mathrm{N}_{2}$ to flow for about 5 seconds.

-- Turn off V3 and allow to pump back down to 40 microns.

-- Repeat above two steps twice more.

-- During the third and final pump down, when the pressure reaches 40 microns, close hand vacuum valve and continue with next section.

v. Heating up the system.

-- Turn on substrate VARIAC on top of table.

-- Increase output slowly by increasing by 10 every few minutes. Ultimately want output at about $50 \%$ which corresponds to about $300^{\circ} \mathrm{C}$ using set I on Athena temperature controller. Note: If fuse on VARIAC burns out, ask Jack in EE. His office is across from EE department office on the third floor of the engineering building. 
Rex has gone as high as $400^{\circ} \mathrm{C}$ using:

Variac output at 608

But at low pressure of $10^{-6}$ torr.

At 1 mtorr and 608 output would probably have

$\mathrm{T}^{-} 430^{\circ} \mathrm{C}$.

The thermocouple measures susceptor temperature, not substrate temperature. So Rex adjusts the TC to about $301-302^{\circ} \mathrm{C}$ at susceptor. Then substrate should be right about $300^{\circ} \mathrm{C}$.

Probably need to make small adjustments in VARIAC

fairly often to keep at setpoint temperature.

-- Now wait 20-30 minutes until set temperatures have been reached

$\begin{array}{lll}\text { Variac } & \text { Output } & \text { Temp } \\ \text { Substrate } & 50 \% & 300^{\circ} \mathrm{C} \\ \text { Burner } & 115 & 970-1000^{\circ} \mathrm{C}\end{array}$

Note: If burner valve is not heating up to $1000^{\circ} \mathrm{F}$, turn down air-to-burner flow (red valve) a little.

-- Can speed up susceptor heat-up by letting in small burst of $\mathrm{N}_{2}$, and then open hand vacuum valve to achieve a little lower pressure, then close hand vacuum valve.

V. Setting up the source gases. 
-- Open $\mathrm{H}_{2} \mathrm{~S}$ cylinder valve and valve leading out of the gasbox.

-- Open DMZn cylinder valve and valve leading out of the gasbox.

-- Flip open Valve 10/11 toggle switch on back of control panel.

-- Open V1 (DMZn) and V2 $\left(\mathrm{H}_{2} \mathrm{~S}\right)$ needle valves.

-- open hand vacuum valve slightly before the next step.

-- Depress buttons labeled "1" and "5" on control panel. This introduces $\mathrm{H}_{2} \mathrm{~S}$ into the reactor chamber and DMZn to bypass. Now will need to adjust hand vac valve to reach 1 mtorr chamber pressure.

VI. Stabilizing flows and commencing deposition.

-- Make sure the pressures, flows, and temperatures are at the desired setpoints.

-- Stabilize pressures and flow rates by setting rotameters to the desired flow, and then adjusting chamber pressure to 1 mtorr using the hand operated vacuum valve above the reaction chamber. Typical rotameter settings are as follows:

$\begin{array}{clc}\text { Valve } & \text { Gas } & \frac{\text { Black/Silver }}{13 / 6} \\ \text { V1 } & \text { DMZn } & 44 / 15.5\end{array}$

-- Let stabilize for 20 minutes. 
-- Switch "1" off and "2" on to introduce DMZn into the reactor chamber and begin deposition.

-- Typical deposit time is about 10 minutes.

\section{After deposition:}

-- On control panel, turn off " 2 " and turn on " 1 " which sends DMZn back to bypass. Let susceptor cool down with $\mathrm{H}_{2} \mathrm{~S}$ still flowing.

-- When susceptor temperature reached $150^{\circ} \mathrm{C}$, turn off "1" and "5" which turns off $\mathrm{H}_{2} \mathrm{~S}$ and DMZn flow.

-- Pressure will start to drop. Now need to cycle $\mathrm{N}_{2}$ through the chamber to clean out toxic gases and help cool the substrate:

1. When pressure reaches 20-30 microns, turn on v3 on control panel.

2. Open vacuum valve more so pressure doesn't reach atmosphere, and also to purge out toxic gases.

3. Wait for 5 minutes.

4. Turn off $V 3$.

5. Repeat steps 1-4 two more times.

-- Turn off substrate VARIAC by turning output back to zero and then flipping off the toggle switch.

-- Close V2, V1 needle valves.

-- Flip off 10/11 toggle switch on back of MOCVD control panel. 
-- Shut off $\mathrm{H}_{2} \mathrm{~S}$ and DMZn cylinders in the gas cabinet.

-- Let susceptor cool to $100^{\circ} \mathrm{C}$.

-- Allow the chamber to come up to atmosphere one last time. When vacuum gauge on top of reactor chamber reads 1 atmosphere, susceptor can be unloaded. Don't forget to unplug the electrical cord and the thermocouples before pulling out the susceptor.

-- Unload the wafer.

-- Put substrate holder back in chamber while opening hand operated vacuum valve.

- Turn off $\mathrm{V} 3 \mathrm{~N}_{2}$ valve.

-- Wait for pressure to reach 30-40 microns.

-- Close hand vacuum valve all the way.

-- Close the two $\mathrm{N}_{2}$ cylinder valves.

-- Turn off burner variac.

-- Turn off burner switch on the control panel.

-- Flip up (open) vac-to-air valve.

-- Turn off mechanical pump switch on control panel.

-- Turn off power supply and turn off main breaker on control panel.

-- Shut off water (yellow valve) and air (red hose).

-- Make sure $\mathrm{H}_{2} \mathrm{~S}$ detector is back in its box with plug in place. 